\begin{tabular}{|l|l|l|l|l|l|}
\hline MUNIBE Antropologia-Arkeologia & $n^{\circ} 66$ & $185-204$ & DONOSTIA & 2015 & ISSN 1132-2217 • eISSN 2172-4555 \\
\hline
\end{tabular}

\title{
La prospección de superficie en la caracterización de yacimientos: poblado protohistórico de Pieza Redonda en Lanciego (País Vasco)
}

\author{
Surface survey in characterization of archaeological sites: \\ Pieza Redonda protohistoric village in Lanciego (Basque Country)
}

PALABRAS CLAVES: Arqueología, Metodología, Paisaje, Territorio, Análisis espacial. GAKO-HITZAK: Arkeologia, Metodologia, Paisaia, Lurraldea, Azterketa espaziala. KEY WORDS: Archaeology, Methodology, Landscape, Territory, Spatial analysis.

José RODRÍGUEZ FERNÁNDEZ ${ }^{(1)}$ \& Ángel MARTíNEZ MONTECELO(2)

\section{RESUMEN}

Hoy día, nadie duda de la eficacia de la prospección superficial como herramienta de valoración, gestión y preservación del patrimonio arqueológico. Sin embargo, su verdadero alcance analítico y cognoscitivo no queda tan claro en la distinta bibliografía existente al respecto. Basándonos en la experiencia obtenida en el yacimiento de Pieza Redonda (Lanciego, Álava), el artículo pretende impulsar una reflexión en torno a las posibilidades, problemáticas y desarrollo teórico-metodológico de la inspección visual dentro de la Arqueología, lo que conlleva necesariamente en nuestra opinión una revisión de conceptos tales como territorio, paisaje y yacimiento.

\section{LABURPENA}

Gaur egun inork ez du azaleko miaketaren eraginkortasuna zalantzan jartzen, ondare arkeologikoaren balioztatze, kudeaketa eta babes erreminta bezala. Halere, bere analitiko eta ezagutzazko garrantzi handia ez da hain argi aipatzen gaiari buruzko existitzen den bibliografian. Pieza Redondan (Lantziego, Araba) lortutako esperientzian oinarrituz, artikuluak Arkeologia barruko ikuste-ikuskapenaren posibilitateen, arazoen eta garapen teoriko-metodologikoaren inguruko hausnarketa bultzatu nahi du. Horrek, lurraldea, paisaia edo aztarnategia bezalako kontzeptuberrikustea berekin dakar nahitaez, gure iritziz.

\section{ABSTRACT}

Nowadays, no one doubts about the effectiveness of surface exploratory drilling as an assessment, management and preservation tool of the archaeological heritage. However, its real analytical and cognitive scope is not clear in the existing bibliography about it. Based on the experience of Piedra Redonda site (Lanciego, Alava), the article aims to promote a reflection on the possibilities, problems and theoretical and methodological development of the visual inspection within archeology, which necessarily involves, in our opinion, the review of concepts such as territory, landscape and site.

The field work and subsequent research work have allowed throughly and objectively delimit the Late Bronze-Early Iron Age environment, but the subsequent historical development of the environment, to the present day, has also been reconstructed. Archaeological research is increasingly receptive to the use of open territorial methodologies, since the traditional concept of the archaeological site as an object of autocratic knowledge (habitat, necropolis, fortress, worship centre, etc.) seems to be over, to focus wider relations and realities, in agreement with historical link between communities and territory (Fairclough, 2002).

\section{1.- CONSIDERACIONES PREVIAS}

El presente artículo gira en torno a los resultados obtenidos en la prospección arqueológica intensiva realizada en 2014 en el yacimiento protohistórico del Poblado de Pieza Redonda (Lanciego, Álava), en el marco de un Campo de Trabajo Arqueológico Internacional auspiciado por el propio ayuntamiento de la localidad y el Gobierno Vasco. El desarrollo de campo y los posteriores trabajos de gabinete han permitido delimitar de forma exhaustiva y objetiva el hábitat del Bronce Final-Primera Edad del Hierro, pero también se ha reconstruido en gran medida el posterior devenir histórico del entorno, hasta nuestros días. Basándonos en esta experiencia, el texto pretende servir de reflexión de cara al cada vez más necesario empleo de metodologías territoriales abiertas, toda vez que el concepto tradicional de yacimiento arqueológico como objeto de co-

\footnotetext{
(1) Universidad del País Vasco - Euskal Herriko Unibertsitatea, Paseo de la Universidad 5, 01006 Vitoria-Gasteiz, jose.rodriguezf@ehu.eus

(2) Gabinete de Arqueología, Patrimonio y Territorio, gaptalava@gmail.com
} 


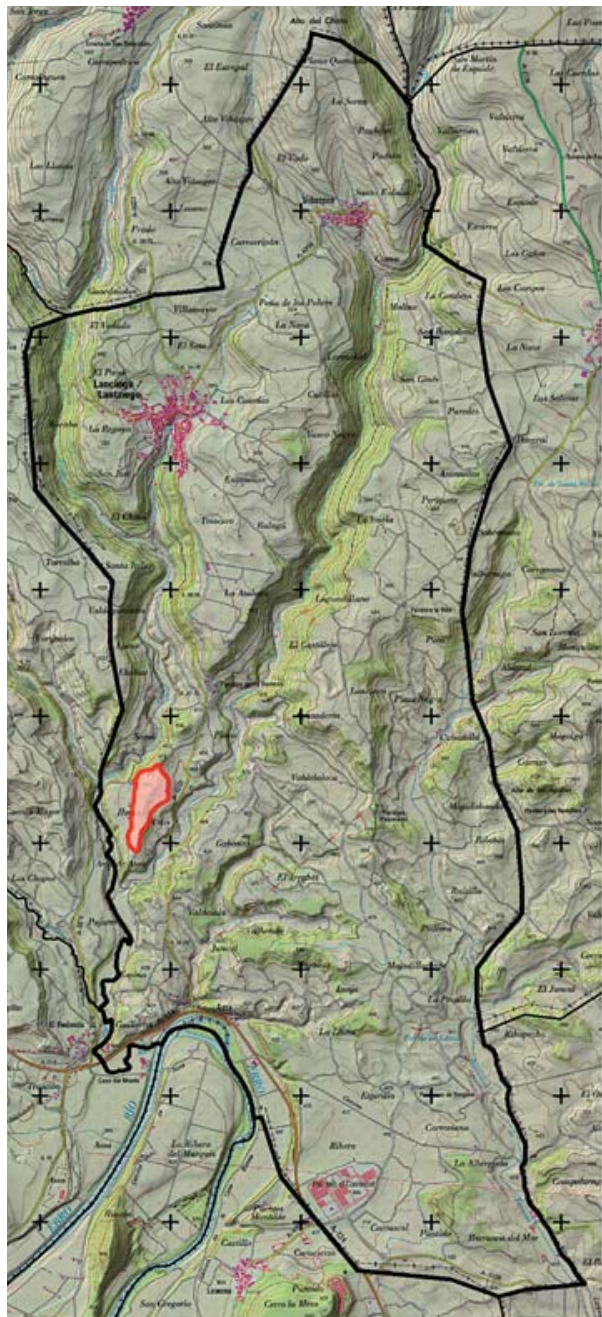

Fig. 1. Localización del yacimiento de Pieza Redonda dentro del municipio de Lanciego/Lantziego (Álava) y delimitación de la zona de estudio / Location of the Pieza Redonda site in the town of Lanciego/Lantziego (Álava) and delimitation of the study area.

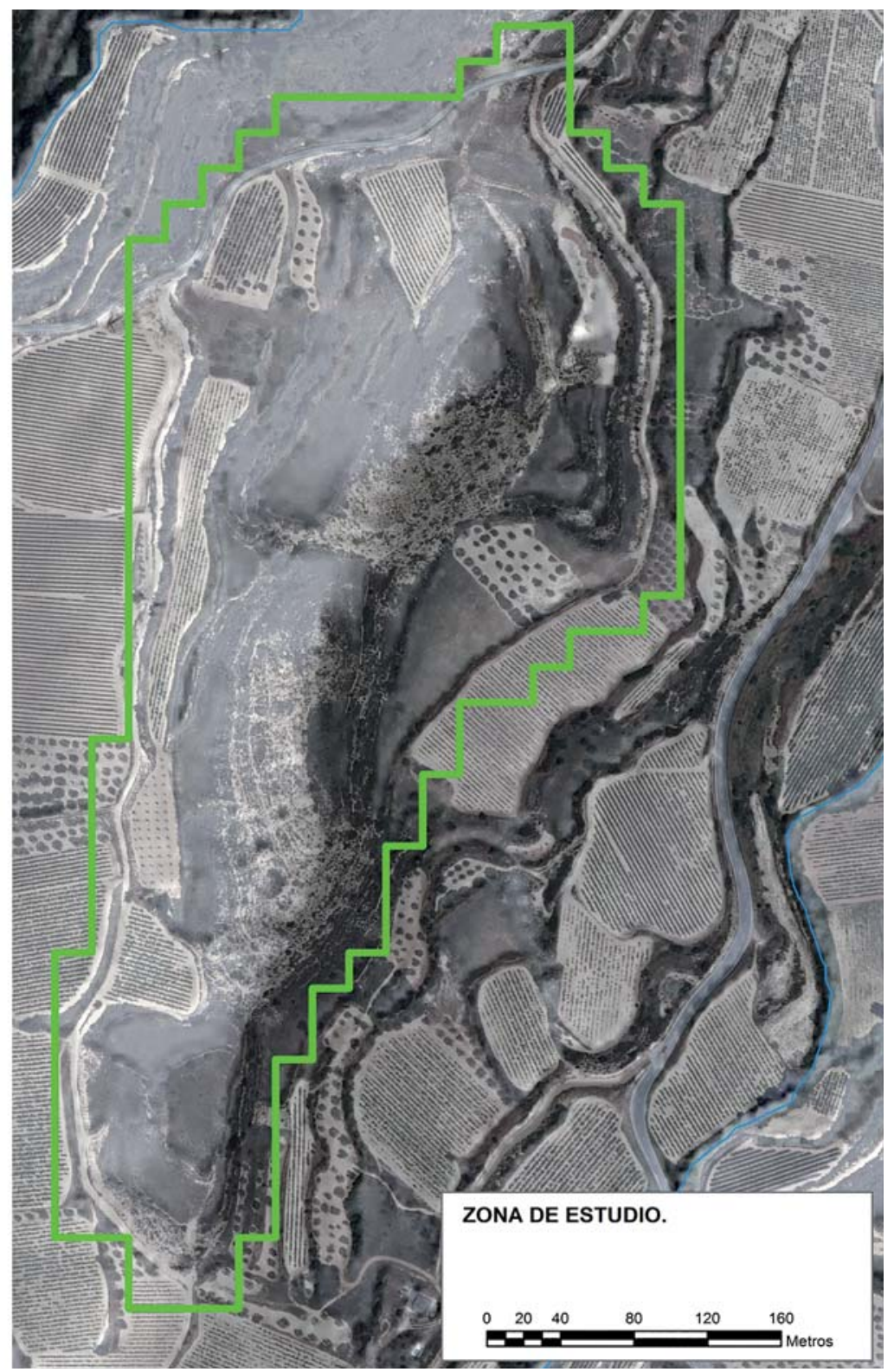

(Álava). Más en concreto, se emplaza en una alineación de pequeños cerros y collados, orientados según el eje NNE-SSW, que quedan delimitados por los arroyos que descienden de Lanciego y Viñaspre. Sin lugar a dudas, se trata de un enclave con interesantes cualidades desde el punto de vista defensivo, estratégico y del control del territorio. Sus coordenadas UTM (ETRS 89) son: X: 539830; Y: 4709275; Z: 496 metros.

Desde el punto de vista geológico y geomorfológico nos encontramos en el contexto de la Depresión del Ebro. Se trata de una sucesión de relieves estructurales con muy leve buzamiento formados por paquetes de areniscas calcáreas y arcillas del Mioceno (Terciario), los cuales articulan el piedemonte que conecta la vega del Ebro con las imponentes crestas de la Sierra de Cantabria. Estos relieves alternan con los barrancos de los arroyos, de carácter 


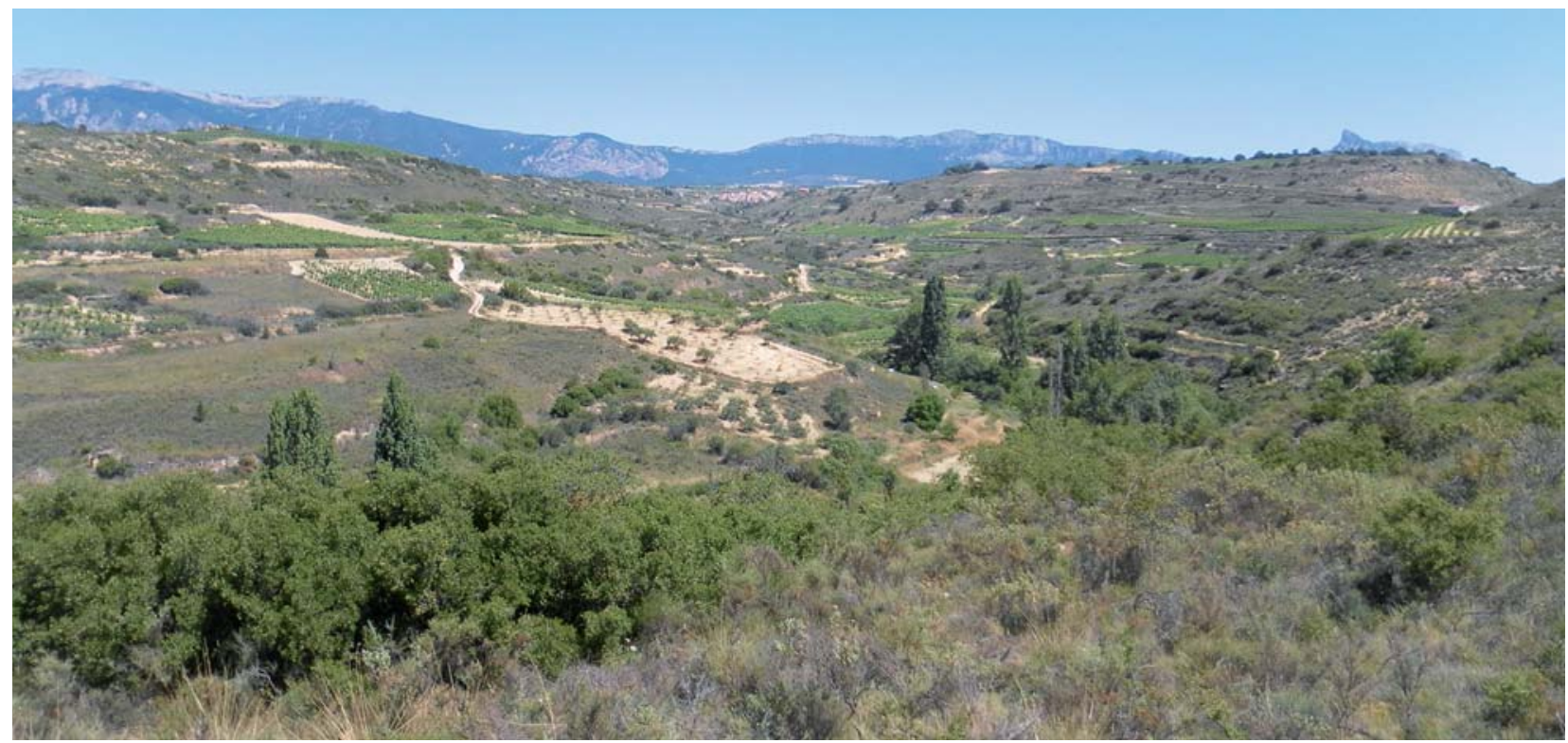

Fig. 2. Vista del paisaje típico del entorno de Pieza Redonda / View of the typical landscape of the Pieza Redonda environment.

semipermanente y torrencial, que inciden profundamente el substrato.

En este entorno se hallan también numerosos y potentes depósitos cuaternarios, testigos de las alternancias climáticas y ambientales acaecidas, sobre todo, durante el Pleistoceno. Prácticamente al pie de la Sierra abundan depósitos de ladera de tipo coluvial. Más abajo encontramos otros tipos de elementos, mucho más habituales en todo el valle del Ebro. Así, mientras que en las laderas existen retazos de glacis detríticos, junto al cauce principal y en sus proximidades se sitúan antiguas terrazas fluviales, muchas de ellas colgadas con su característica morfología de cerro amesetado.

Desde el punto de vista climático se trata de un escenario plenamente mediterráneo, con una gran diversidad de matices internos según la altitud y la exposición, de modo que en los apenas diez kilómetros que median entre Assa junto al Ebro y las cumbres de la Sierra al norte encontramos una gran diversidad de ambientes. En el entorno de Pieza Redonda el clima es el típico del Valle del Ebro, con una temperatura media anual de unos $13^{\circ} \mathrm{C}$ y unas precipitaciones en torno a $500 \mathrm{~mm}$. Ante estas condiciones, la vegetación potencial estaría formada por encinares y carrascales que alternarían con algunas manchas de quejigo en las zonas más elevadas y con unas galerías de vegetación de ribera que ocuparía los valles más húmedos y con potentes suelos. Sin embargo, poco queda de esa vegetación primigenia. En la actualidad son escasos los espacios de este entorno que no han sufrido algún tipo de aprovechamiento, de modo que la mayor parte de la zona se encuentra ocupada por parcelas dedicadas al viñedo y al olivar, con islotes residuales de matorral mediterráneo muy deteriorado (coscojas, enebros, aulagas, ...) en general bastante espinoso e impenetrable. Incluso en algunos sectores la cobertura vegetal está tan deteriorada que el suelo aparece muy erosionado y apenas se conserva regolito.

\subsection{Contextualización arqueológica del yacimiento}

El diseño y desarrollo de la prospección requiere de unas labores previas o simultáneas a la inspección visual del terreno. No vamos a ocuparnos de ellas en este artículo por cuestiones de espacio, pero al menos sí recordaremos la conveniencia de realizar vaciados documentales, bibliográficos, toponímicos, cartográficos y escrutar la información oral mediante entrevistas-encuestas dirigidas a informantes seleccionados (MARTÍNEZ y RODRÍGUEZ, 2013). Centrándonos ya en la identificación material, hemos de señalar en primer lugar que no existían prácticamente referentes arqueológicos de Pieza Redonda con anterioridad a la intervención de 2014, y menos aún referencias publicadas (LLANOS, 1995). Por otra parte, y en el ámbito de la gestión patrimonial, el yacimiento carece actualmente de grado de protección jurídica oficial, hecho que puede variar próximamente si los resultados de la caracterización del conjunto son considerados adecuados por parte de las administraciones correspondientes.

Las primeras labores de las que se tiene constancia son los trabajos de prospección realizados de forma sistemática por el Instituto Alavés de Arqueología durante las décadas de los 60, 70 y 80 del siglo pasado para la elaboración de la Carta Arqueológica de Álava (LLANOS, 1987). En cualquier caso, la aparición "oficial" del yacimiento tiene lugar en 1985 de la mano, de nuevo, de Armando Llanos, bajo la denominación por aquel entonces de Alto de la Paloma. Desde el principio se interpretó como un poblado protohistórico, con una secuencia cultural que abarcaba desde el Bronce Final a la Primera 
Edad del Hierro. Según la tipología diseñada por el mismo autor, Pieza Redonda respondería al tipo D2, esto es, un hábitat que ocupa principalmente la ladera de un cerro y que se articula, siguiendo las propias características orográficas del lugar y los restos de estructuras visibles, mediante varios cinturones concéntricos de terrazas y/o defensas. (LLANOS, 1974).

Después, cabe mencionar una prospección extensiva realizada por Eliseo Gil e Idoia Filloy en 1994, que sirvió para la redacción de una breve ficha que describe el poblado, consultable en el Museo de Arqueología de la Diputación Foral de Álava (Bibat). Entre los materiales depositados a raíz de esta intervención de 1994 hay un único fragmento de terra sigillata que contrasta con la producción cerámica recogida antes (1985) y después (2014). También, pero ya sin incidencia directa sobre el yacimiento, hay que tener en cuenta los denominados Inventarios de Patrimonio arquitectónico. Elementos Menores, cuyo trabajo de campo en esta Cuadrilla administrativa se realizó entre el año 2001 y 2002 (PALACIOS y RODRÍGUEZ, 2004), y que recogen arquitecturas que transitan por el ambiguo limbo existente entre el patrimonio etnográfico y el histórico-arqueológico. Se documentaron más de un centenar de elementos entre abejeras, chozos, corrales, fuentes, rollos, molinos, trujales, puentes, pozos de nieve, regadíos o tejeras. Precisamente, experiencias como la del conjunto tejero de El Encinal Ilevadas a cabo en los últimos años demuestran que estas estructuras tienen una lectura plenamente arqueológica (RODRÍGUEZ, SÁNCHEZ y PALACIOS, 2005). Finalmente, durante los últimos treinta años se ha realizado una media docena de intervenciones arqueológicas puntuales en el municipio, la mayoría de ellas recogidas en la revista Arkeoikuska.
Nos interesa destacar que el punto de partida donde situar el objeto de estudio era bastante difuso, y presentaba varias deficiencias totalmente extrapolables a cualquier otra situación o ámbito histórico-arqueológico. Según el Centro de Patrimonio Cultural de Gobierno Vasco, dentro del término municipal de Lanciego se encuentran ocho yacimientos arqueológicos, a los que habría que añadir otras tantas entidades arqueológicas entre los yacimientos y hallazgos aislados incluidos en el Museo Provincial de Álava y en la Carta Arqueológica de Álava (LLANOS, 1987). El listado-cualquiera de ellos- sigue abierto, porque existen elementos de interés arqueológico sin identificar y, por ende, sin entrar en los circuitos oficiales de gestión y conservación. Prueba de ello es que, tras una visita de campo realizada el 30 de abril de 2012 en compañía de algunos vecinos de Viñaspre (Lanciego), constatamos la existencia de evidencias materiales de diversa naturaleza y cronología (un lagar rupestre, zonas de acumulación de material prehistórico y los restos de una ermita).

En definitiva, cuando tratamos de esbozar un estado de la cuestión previo a la investigación, hemos de tener en cuenta que muchos elementos relevantes del paisaje histórico no son visibles en los distintos inventarios, cartas y bases de datos de gestión y, por supuesto, carecen de investigaciones pormenorizadas de calidad, fruto de actuaciones diacrónicas, parciales, inconexas y con objetivos y metodologías -cuando existen- distintas. De la misma manera que asumimos de forma crítica los datos provenientes de la información oral, documental o toponímica, las referencias materiales que ayudan a contextualizar el yacimiento deben también considerarse con sus problemáticas, ambigüedades y vacíos.

\begin{tabular}{|c|c|c|c|c|}
\hline Año & Yacimiento & Tipo & Referencia & Observaciones \\
\hline 1985 & Yacimientos por toda Álava & Prospección & $\begin{array}{l}\text { Informes del IAA } \\
\text { Arkeoikuska 1985, pp. 82-85 }\end{array}$ & Descubrimiento de Pieza Redonda \\
\hline 1994 & Pieza Redonda. Lanciego & Prospección & $\begin{array}{l}\text { Ficha en el Bibat. No hay } \\
\text { referencia en Arkeoikuska }\end{array}$ & $\begin{array}{l}\text { Dentro de los trabajos de } \\
\text { inventariado de yacimientos } \\
\text { por parte de la DFA }\end{array}$ \\
\hline 1998 & Viña Assa. Lanciego & Excavación & Arkeoikuska 1998, pp. 208-211 & Entorno del Puente de Mantible \\
\hline 2001 & $\begin{array}{l}\text { Término municipal } \\
\text { completo }\end{array}$ & Prospección & Palacios y Rodríguez, 2004 & $\begin{array}{c}\text { Inventario de Patrimonio } \\
\text { Arquitectónico de la Cuadrilla } \\
\text { de Laguardia - Rioja Alavesa. } \\
\text { Elementos Menores }\end{array}$ \\
\hline \multirow[t]{2}{*}{2002} & $\begin{array}{c}\text { Varios yacimientos en } \\
\text { Lanciego y otros municipios }\end{array}$ & Prospección & $\begin{array}{l}\text { Arkeoikuska 2002, pp. } \\
\text { 293-294 }\end{array}$ & $\begin{array}{l}\text { Prospección dentro del contexto del } \\
\text { seguimiento de una red de riego }\end{array}$ \\
\hline & $\begin{array}{c}\text { Varios yacimientos en } \\
\text { Lanciego y otros municipios }\end{array}$ & Control de obras & Arkeoikuska 2002, pp. 308-311 & - \\
\hline 2003 & $\begin{array}{l}\text { Iglesia de Viñaspre. } \\
\text { Lanciego }\end{array}$ & Lectura de alzados & $\begin{array}{l}\text { Arkeoikuska 2003, pp. } \\
257-259\end{array}$ & - \\
\hline 2004 & $\begin{array}{l}\text { Tejera del El Encinal. } \\
\text { Lanciego }\end{array}$ & Excavación & $\begin{array}{c}\text { Arkeoikuska 2004, pp. } \\
184-195\end{array}$ & Intervención en un Elemento Menor \\
\hline 2012 & $\begin{array}{l}\text { Lagar de Larrachal. } \\
\text { Viñaspre, Lanciego }\end{array}$ & Excavación & Arkeoikuska 2012, pp. 92-93 & Intervención en un Elemento Menor \\
\hline
\end{tabular}

Tabla 1: Listado las intervenciones de carácter arqueológico realizadas en el municipio de Lanciego durante las últimas tres décadas / List of archaeological interventions carried out in the town of Lanciego over the past three decades. 


\subsection{Objetivos de la intervención}

Como ya hemos avanzado, la prospección superficial del área pretendía servir a los siguientes fines:

1. Reivindicar las potencialidades de la prospección arqueológica sistemática, tanto en sí misma como actividad previa a la excavación. Tradicionalmente, este procedimiento ha estado en cierto modo sometido a las normas que dictaba la excavación, siendo considerada como una labor auxiliar de ésta, aunque en la bibliografía contemporánea al respecto goza ya de una cierta validez analítica (FERNÁNDEZ MARTíNEZ, 1989; CAMBI, 2001; BANNING, 2002; BURILLO, 2013).

2. Valorar de forma objetiva los resultados a partir del análisis espacial de los datos obtenidos en campo. Entre otros:

- Dispersión de los tipos de materiales.

- Dispersión de la cronología de los materiales.

- Dispersión y densidad de la cerámica protohistórica.

- Cartografiar las estructuras construidas detectadas dentro de la delimitación del yacimiento.

3. Finalmente, proporcionar herramientas para ayudar en la toma de decisiones de la praxis arqueológica cotidiana, en ésta y otras intervenciones. Si tenemos en cuenta que en gran parte de los yacimientos arqueológicos de nuestro entorno la mayoría de la información proviene de prospecciones extensivas y -casi siempre- no sistemáticas, puede ser interesante generar un protocolo de actuación para casos comparables.

\section{2.- METODOLOGÍA}

\subsection{Características de la prospección arqueológica}

Comenzábamos el artículo poniendo de manifiesto la dificultad de ofrecer una definición sintética de lo que es la prospección arqueológica, debido a la multiplicidad de puntos de vista, objetivos y recorridos que el concepto posee. En esta línea, la mayoría de investigadores también lamentan la ausencia de una metodología unificada (BURILLO, 2013: 16-17). Todo ello ha originado una bibliografía abundante pero también dispersa, con numerosos artículos y unas pocas recopilaciones de trabajos, pero sin ningún manual o texto específico en castellano hasta hace bien poco tiempo (CAMBI, 2001; BANNING, 2002; CHAPA et al, 2003; QUIRÓS Y GOBBATO, 2004; GARCÍA SANJUÁN, 2005; BURILLO, 2013).

En un reciente trabajo, Francisco Burillo Mozota (2013: 17-21) clasificaba las intervenciones de prospección en base a sus motivaciones y objetivos, estableciendo tres tipos principales en función de si el proceso está vinculado (1) a la arqueología de urgencia que precede a una infraestructura urbanística o de ingeniería, (2) a los inventarios de patrimonio promovidos principalmente desde las administraciones para una gestión y conservación del patrimonio, y (3) a la investigación histórico-arqueológica, como es el caso que nos ocupa.

Pasamos a desgranar con detenimiento las principales características de la intervención efectuada en Pieza Redonda; la conjunción de todas ellas (a modo de cluster de variables) ofrecerá una visión reveladora:

- Respecto a la existencia o no de un diseño previo, el trabajo se define sin duda como una prospección arqueológica sistemática en cuanto a planteamientos y desarrollo.

- La intervención se ha ceñido estrictamente a una inspección visual de la superficie, sin que se contemplara -al menos en la campaña de 2014- la realización de ninguna otra actividad como podrían ser catas, sondeos o prospección geofísica.

- En cuanto a la cobertura del terreno, se trata de una prospección de cobertura total. Teniendo en cuenta la extensión de la zona de estudio (14,2 Ha), el número de prospectores (15-17 personas) y el tiempo disponible (20 jornadas de 5 horas), se consideró que era objetivamente posible inspeccionar la totalidad del yacimiento.

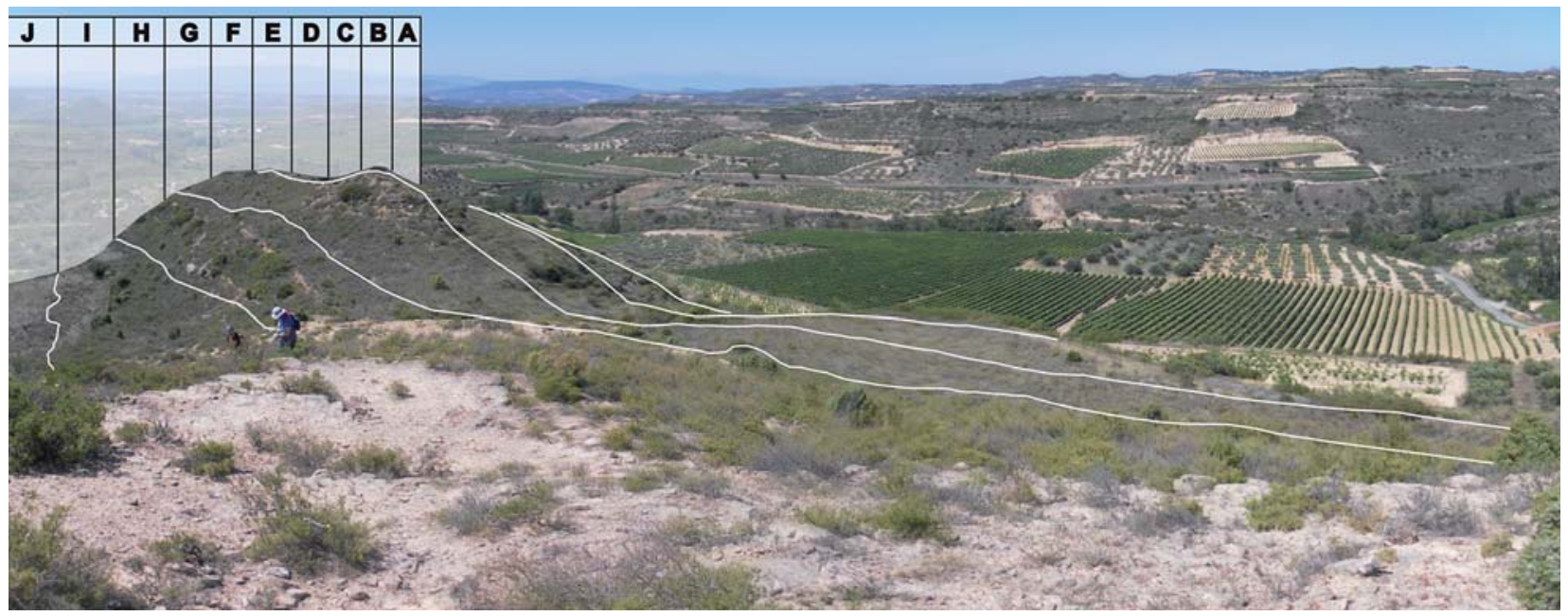

Fig. 3. Labores de replanteo de los transectos, previas a los trabajos de prospección / Work staking transects, prior to the surface survey. 


\begin{tabular}{|c|c|c|c|c|}
\hline CRITERIO & \multicolumn{3}{|c|}{ TIPO DE PROSPECCIÓN } & PIEZA REDONDA, 2014 \\
\hline \multirow{6}{*}{$\begin{array}{l}\text { Según la } \\
\text { cobertura } \\
\text { de terreno }\end{array}$} & \multicolumn{3}{|l|}{ Cobertura total } & $x$ \\
\hline & \multirow{5}{*}{ Muestreo } & \multirow{2}{*}{ Muestreo aleatorio } & Muestreo aleatorio simple & - \\
\hline & & & Muestreo aleatorio estratificado & - \\
\hline & & \multirow{2}{*}{ Muestreo sistemático } & Muestreo sistemático alineado & - \\
\hline & & & Muestreo sistemático no alineado & - \\
\hline & & \multicolumn{2}{|l|}{ Muestreo estratificado } & - \\
\hline \multirow{2}{*}{$\begin{array}{l}\text { Según } \\
\text { la intensidad }\end{array}$} & \multicolumn{3}{|l|}{ Intensiva } & $x$ \\
\hline & \multicolumn{3}{|l|}{ Extensiva } & - \\
\hline \multirow{4}{*}{$\begin{array}{l}\text { Según la forma } \\
\text { de las unidades } \\
\text { de muestreo }\end{array}$} & \multicolumn{3}{|l|}{ Transectos } & $x$ \\
\hline & \multicolumn{3}{|c|}{ Cuadrados o cuadrículas } & - \\
\hline & \multicolumn{3}{|l|}{ Circulares } & - \\
\hline & \multicolumn{3}{|l|}{ Irregulares } & - \\
\hline \multirow{4}{*}{$\begin{array}{l}\text { Según el } \\
\text { movimiento } \\
\text { de tierras }\end{array}$} & \multirow{2}{*}{$\begin{array}{l}\text { Sin movimiento } \\
\text { de tierras }\end{array}$} & \multicolumn{2}{|l|}{ Prospección visual } & $x$ \\
\hline & & \multicolumn{2}{|l|}{ Prospección geofísica } & - \\
\hline & \multirow{2}{*}{$\begin{array}{l}\text { Con movimiento } \\
\text { de tierras }\end{array}$} & \multicolumn{2}{|l|}{ Prospección con catas } & - \\
\hline & & \multicolumn{2}{|l|}{ Prospección mecánica } & - \\
\hline
\end{tabular}

Tabla 2: Principales características de la prospección arqueológica realizada en Pieza Redonda, 2014 / Main characteristics of the archaeological survey in Pieza Redonda, 2014

- Los recorridos de campo tienen forma de transectos rectangulares orientados según el eje Norte-Sur, con una anchura de 20 metros cada uno, los cuales han sido codificados de Oeste a Este comenzando con el Transecto- $A$ hasta el Transecto- $Q$. La longitud de los transectos varía entre 160 metros (Transecto-A) y 620 metros (Transecto-E). La cuestión de si la forma de los recorridos de campo y las unidades de muestreo deben tener una forma regular o no ha sido objeto de debate entre diversas escuelas (BURILLO, 2013: 24). En nuestra opinión, la naturaleza y objetivos de la investigación marca el camino a seguir; nosotros mismos hemos optado por recorridos más "orgánicos" en espacios forestados abruptos (MARTíNEZ y RODRÍGUEZ, 2013). En el caso de Pieza Redonda se optó por la realización de transectos regulares con el fin de parcelar de la misma forma todo el espacio estudiado, a pesar de que el territorio nunca o casi nunca se ajusta esos límites (BANNING, 2002). Sin embargo, esa regularidad es fundamental para poder realizar una interpolación de las evidencias detectadas al conjunto del yacimiento. Previamente a los recorridos de campo fue necesaria la realización del replanteo del trazado de los transectos con estacas y cintas.

- En cuanto a la escala de trabajo ajustada a los objetivos: repartidos en los 20 metros de anchura del transecto se colocaron en intervalos regulares entre 5 y 7 prospectores, de modo que podemos considerar que se trata de una prospección intensiva.

- Finalmente, los límites de la zona de estudio son, en esencia y como puede observarse en la cartografía que ofrecemos junto al texto, los proporcionados por el Centro de Patrimonio Cultural de Gobierno Vasco, adaptados a los objetivos del trabajo.

\subsection{Unidades y registro de la información}

Una de las grandes dudas a las que se enfrenta la prospección arqueológica es la de qué registrar o, dicho de forma parecida, qué entidades arqueológicas documentar. Lógicamente esta cuestión ha de ser coherente con los objetivos y la escala del análisis. Siguiendo la obra de L. García Sanjuán (2005: esp. 169) encontramos una interesante síntesis de las diferentes propuestas, que reflejamos de mayor a menor escala de análisis, lo que dicho sea de paso muestra una vez más que el registro arqueológico es continuo, difuso y de densidad variable sobre el territorio. Debido a ello, la documentación y protección de entidades arqueológicas que no se ajusten al término de yacimiento (registro off site) ofrece serios problemas y grandes retos al gremio arqueológico:

- Hallazgo aislado: Lugar de localización de artefactos y/o elementos arquitectónicos carentes de asociación sistemática.

- Unidad: Parte de un yacimiento arqueológico que satisface al menos uno de una serie de criterios legales, urbanísticos o funcionales.

- Sitio: Conjunto de restos materiales derivados de la actividad humana y con una continuidad espacial, que requieren el uso fundamental de la metodología arqueológica para su estudio.

- Área: Conjunto de yacimientos arqueológicos que aparecen integrados dentro de un paisaje caracterizado por valores culturales específicos.

La unidad básica de registro arqueológico en nuestra intervención ha sido la Unidad de Prospección (en adelante, UP), de naturaleza muy similar al Hallazgo aislado descrito. Sin embargo, existen algunas cuestiones que añadimos de cara a una mejor definición y comprensión 
de la unidad, y que merece la pena tratar a continuación. Una UP, en función de sus características geométricas y la escala de trabajo, puede ser puntual (por ejemplo, una evidencia cerámica aislada, un fragmento de molino de mano, un mojón antiguo,...), lineal (un muro, un viejo camino, un canal, ...) o bien zonal (una concentración de cerámica, un suelo, una cabaña,...).

Así, cada UP está constituida o subdividida por uno (en el caso de las puntuales) o varios (en el caso de las lineales y zonales) elementos homogéneos entre sí (en tipología y cronología), dispuestos en una concentración delimitada o fácilmente delimitable (por ejemplo, una concentración de cerámicas vidriadas, un muro de similar aparejo). ¿Cómo resolver su identificación y documentación? Denominamos a estos subelementos Puntos Georreferenciados de la Unidad de Prospección (PGUP), obtenidos mediante navegador GPS. Los PGUP son, por tanto, las unidades básicas de registro espacial en esta intervención. Son cada uno de los puntos documentados con unas coordenadas concretas que sirven para definir la posición, la forma y la extensión de una UP arqueológica. Como venimos comentando, el número de PGUP de una UP depende de varios factores, tales como la escala de trabajo, la naturaleza geométrica (puntual, lineal o zonal) de la unidad, etc. La descomposición de las UP en PGUP es fundamental para poder convertir la información puntual en información lineal o zonal y, como puede observarse en la figura siguiente, abre la puerta al análisis espacial a través de ciertas relaciones topológicas (igual a / incluido en
/ incluye a / solapamiento parcial con / contiguo a /próximo a) que, incluso, pueden llegar a permitir una lectura en clave de anteroposterioridad al modo de las Unidades Estratigráficas. Comenzamos ensayando estas cuestiones en el proyecto Aplicación del cluster analysis al paisaje: los Montes de Vitoria, llevado a cabo por Enklabe Arqueología y Topografia en colaboración con el Grupo de Investigación en Patrimonio Construido (MARTíNEZ y RODRÍGUEZ, 2013). De hecho, las UPs no tienen que ser arqueológicas necesariamente, también pueden poseer otro carácter como, por ejemplo, toponímico, documental o cualquier otro tipo de información que nos interese fácilmente cartografiable. Esto es muy útil para trabajos como Estudios de Paisaje y, en general, siempre que resulte de interés vincular una información al territorio.

En Pieza Redonda, cada uno de los hallazgos ha sido codificado con, por lo menos, un punto o PGUP, cuya sigla comienza con la letra del transecto $(A, B, C, \ldots)$; después de ésta tres dígitos que hacen referencia a número de Unidad de Prospección dentro del transecto (A001, A002, $A 003, \ldots)$ y, finalmente, se anota el número concreto de punto (PGUP) dentro de la UP (A001-01, A001-02, A001$03, \ldots)$. Este tratamiento permite, en función de distintos intereses analíticos, mostrar la distribución y densidad de evidencias puntuales y tipos de material (cartografía elaborada a nivel de PGUP) o ampliar la escala hasta cierto tipo de Unidades de Prospección -por ejemplo muros y regaderas- que requieren un estudio más pormenorizado de carácter cronotipológico.

\begin{tabular}{|l|l|l|l|}
\hline Unidad básica de registro & Denominación & Naturaleza geométrica & Ejemplo de código \\
\hline Arqueológico & Unidad de Prospección (UP) & Puntual, lineal o zonal & P027 \\
\hline Espacial & $\begin{array}{l}\text { Punto Georreferenciado de la Unidad } \\
\text { de Prospección (PGUP) }\end{array}$ & Puntual & P027-01 \\
& & & P027-02 \\
& & & P027-03 \\
\hline
\end{tabular}

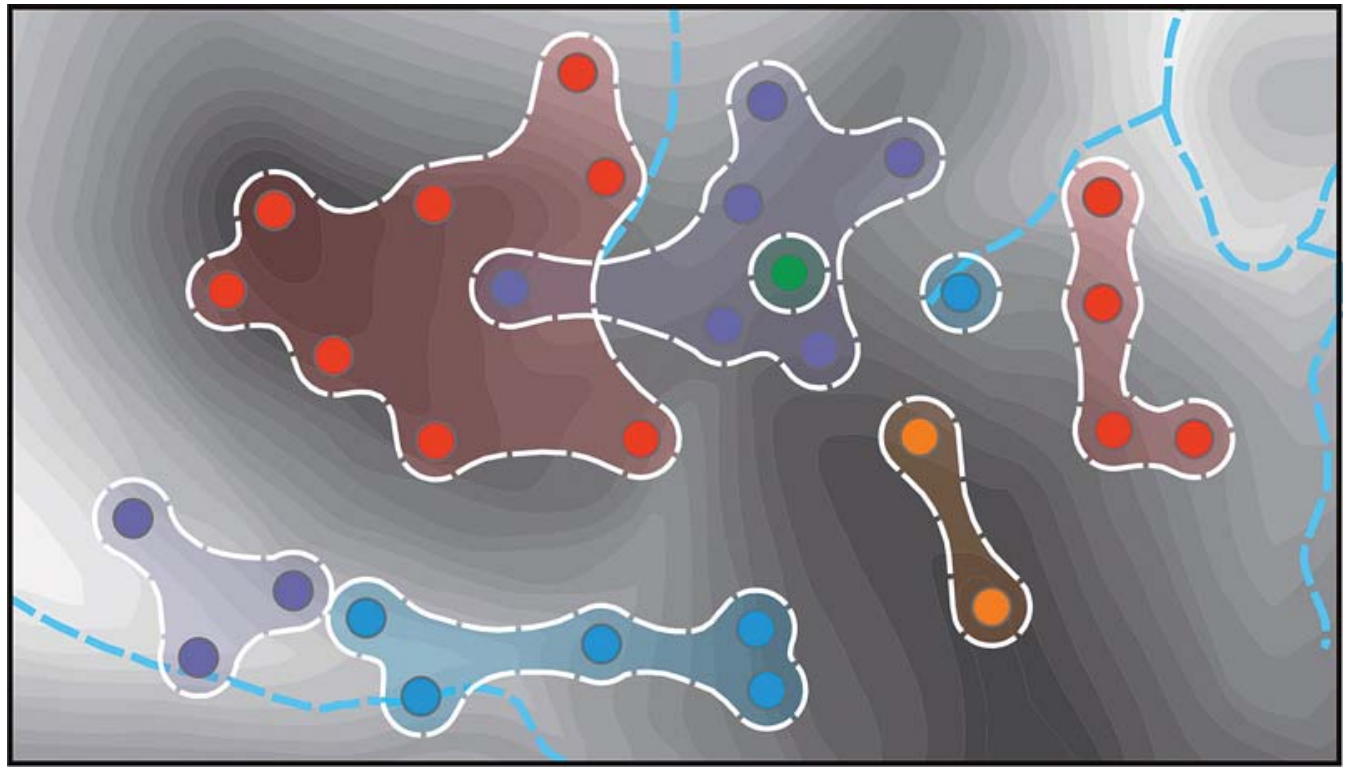

Tabla 3: Unidades de registro utilizadas y ejemplo teórico de la descomposición de las Unidades de Prospección (UP) en Puntos Georreferenciados de la Unidad de Prospección (PGUP) / Register units used and theoretical example of the breakdown of Survey Units (UP) in Georeferenced Points of Survey Unit (PGUP). 


\subsection{La gestión de los hallazgos: algunos límites y potencialidades}

La tendencia actual en prospección (CAMBI, 2001; BANNING, 2002; GARCÍA SANJUÁN, 2005; BURILLO, 2013) considera que la mejor opción es conservar el material in situ. Sin embargo, la naturaleza de la intervención (con un amplio número de personal escasamente formado en Arqueología) y el estado del material (mayoritariamente de pequeñas dimensiones, degradado y bastante sucio) hacían difícil su correcto reconocimiento en campo, de modo que se decidió recoger la mayoría de las evidencias una vez georreferenciadas, para su posterior análisis en laboratorio. Evidentemente, fuera de este ámbito quedan las estructuras imbricadas en el paisaje.

Uno de los precios que tiene la delimitación de las zonas de muestreo con formas regulares es el registro diferencial, fruto de un grado de visibilidad desigual. Cons-

\begin{tabular}{|c|c|c|c|c|}
\hline TIPO & SUBTIPO & DENTRO & FUERA & TOTAL \\
\hline Cerámica doméstica & C. Br. Final-Hierro I & 565 & 7 & 572 \\
\hline Cerámica doméstica & C. Celtibérica & 1 & 0 & 1 \\
\hline Cerámica doméstica & C. Romana & 0 & 0 & 0 \\
\hline Cerámica doméstica & C. Medieval & 5 & 0 & 5 \\
\hline Cerámica doméstica & C. Moderna & 34 & 9 & 43 \\
\hline Cerámica doméstica & C. Contemporánea & 266 & 35 & 301 \\
\hline Cerámica doméstica & C. Indeterminada & 24 & 1 & 25 \\
\hline \multicolumn{2}{|c|}{ TOTAL CERÁMICA DOMÉSTICA } & 895 & 52 & 947 \\
\hline Cerámica constructiva & Teja Moderna & 3 & 0 & 3 \\
\hline Cerámica constructiva & Teja Contemporánea & 15 & 5 & 20 \\
\hline Cerámica constructiva & Ladrillo Moderno & 0 & 0 & 0 \\
\hline Cerámica constructiva & Ladrillo Contemporáneo & 1 & 0 & 1 \\
\hline Cerámica constructiva & C. Constr. Indeterminada & 2 & 0 & 2 \\
\hline Cerámica constructiva & Azulejos & 2 & 0 & 2 \\
\hline \multicolumn{2}{|c|}{ TOTAL CERÁMICA CONSTRUCTIVA } & 23 & 5 & 28 \\
\hline Lítico & Molinos de mano & 6 & 0 & 6 \\
\hline Lítico & Pulimentos & 7 & 0 & 7 \\
\hline Lítico & Alisadores & 3 & 0 & 3 \\
\hline Lítico & $\begin{array}{l}\text { Pequeños restos útiles } \\
\text { sílex/cuarcita }\end{array}$ & 5 & 0 & 5 \\
\hline \multicolumn{2}{|c|}{ TOTAL LÍTICO } & 21 & 0 & 21 \\
\hline Metal & Clavo & 1 & 0 & 1 \\
\hline Metal & Proyectil & 1 & 0 & 1 \\
\hline Metal & Reja de arado & 1 & 0 & 1 \\
\hline \multicolumn{2}{|c|}{ TOTAL METAL } & 3 & 0 & 3 \\
\hline Óseo & Óseo animal & 4 & 0 & 4 \\
\hline \multicolumn{2}{|c|}{ TOTAL ÓSEO } & 4 & 0 & 4 \\
\hline Estructuras y cortes & Muros & 176 & 8 & 184 \\
\hline Estructuras y cortes & Chozos & 11 & 0 & 11 \\
\hline Estructuras y cortes & Regaderas & 66 & 2 & 68 \\
\hline Estructuras y cortes & Estruct. Indeterminadas & 6 & 0 & 6 \\
\hline \multicolumn{2}{|c|}{ TOTAL ESTRUCTURAS Y CORTES } & 259 & 10 & 269 \\
\hline \multicolumn{2}{|c|}{ TOTAL HALLAZGOS } & 1205 & 67 & 1272 \\
\hline
\end{tabular}

Tabla 4: Hallazgos documentados en la prospección, diferenciando el tipo de material, su cronología y si se encuentra dentro o fuera de la zona de estudio (aunque próximo a sus límites, en cualquier caso) / Findings documented during the survey, distinguishing the type of material, its chronology and whether it is within or outside the study area (but close to its limits, in any case). cientes de esa limitación hemos diferenciado seis tipos de coberturas del suelo que generan diversos rangos de visibilidad en función del tipo de material y su tamaño, que nos ayudan a valorar y poder comparar en gran medida la cantidad de hallazgos entre los diferentes cuadrantes.

- Zonas intensamente erosionadas (1): son los espacios con mayor visibilidad para cualquier tipo de evidencia. Se circunscriben a ciertos sectores del área cimera y laderas de los cerros, especialmente en el septentrional. A pesar de la alta densidad de hallazgos, como contrapartida tenemos la seguridad de que no hay en absoluto concordancia entre los restos en superficie y en el subsuelo, simplemente porque apenas se conserva regolito.

- Zonas de cultivo de leñosas (2): se trata de zonas ocupadas con olivar y, sobre todo, viñedo. Se distribuyen por casi todo el perímetro de la zona de estudio y permiten una alta visibilidad. Sin embargo, es realmente curiosa la ausencia de material protohistórico en estos sectores donde en cambio abunda el material postmedieval. El intenso laboreo, así como posibles aterrazamientos y movimientos de tierras quizás expliquen estas ausencias.

- Zonas con vegetación (3-6): Los residuos de vegetación natural están protagonizados por coscojas, enebros y aulagas con una cobertura y densidad variable, además de pastos xerófilos sellando los huecos. En función de la densidad y la cobertura, los materiales muebles de pequeño tamaño son cada vez menos visibles. Es el tipo de cobertura más extendido dentro de la zona de estudio y se corresponde con zonas antes explotadas, pero hoy día abandonadas a causa de la dificultad para su mecanización y, en consecuencia, escasa rentabilidad.

Otro problema que cada vez lo es menos es la representación cartográfica de los hallazgos y las interpretaciones extraídas de los mismos. En este sentido, hay que recordar que la relación entre los SIG y la Arqueología ha llegado fundamentalmente a través de trabajos de prospección realizados a escala territorial (por ejemplo, en Inventarios de Patrimonio Arqueológico) donde ha sido necesario gestionar una gran cantidad de información espacial. Las publicaciones en castellano son numerosas y arrancan con un trabajo de síntesis pionero titulado Los SIG y el Análisis Espacial en Arqueología (BAENA, BLASCO y QUESADA, 1999) y continúan con

\begin{tabular}{|l|c|c|c|c|}
\hline \multicolumn{1}{|c|}{ USO DEL SUELO } & \multicolumn{4}{c|}{ VISIBILIDAD DE MATERIALES } \\
& Cerámica & Pulimentos & $\begin{array}{c}\text { Muros, } \\
\text { chozos,... }\end{array}$ & Regaderas \\
\hline 1. Zonas intensamente erosionadas & 5 & 5 & 5 & 5 \\
\hline 2. Zonas de cultivo de leñosas & 4 & 4 & 5 & 4 \\
\hline 3. Zonas de matorral disperso & 3 & 3 & 4 & 3 \\
\hline 4. Zonas de hierba y matorral disperso & 3 & 3 & 3 & 2 \\
\hline 5. Zonas de hierba y matorral abundante & 1 & 1 & 2 & 1 \\
\hline 6. Zonas muy densas en hierba y matorral & 0 & 0 & 1 & 0 \\
\hline
\end{tabular}

Tabla 5: Rangos de visibilidad en la zona de estudio en función la cobertura del suelo.

Visibilidad: 5 = Muy buena; 4 = Buena; 3 = Media; 2 = Mala; 1 = Muy mala; 0 = Nula Visibility ranges in the study area based on land cover.

Visibility: 5 = Very good; 4 = Good; 3 = Average; 2 = Poor; 1 = Very bad; 0 = Null. 
algunas traducciones más recientes de autores anglosajones (CONOLLY y LAKE, 2009). A pesar de sus grandes potencialidades, no es tan habitual utilizar este tipo de software a una escala de trabajo mayor, como en excavaciones y en lecturas de alzados, donde están más presentes programas de diseño asistido por ordenador.

Incluso no faltan investigadores (BURILLO, 2013: 23) que aventuran algunos inconvenientes y malentendidos en el empleo de Sistemas de Información Geográfica, que pueden sobrevenir de un tratamiento inadecuado de la información (especialmente en el contexto de auditorías medioambientales, ingenierías, etc.), al no conocer las limitaciones de los datos. Hay que asumir que la información arqueológica pocas veces es segura y definitiva, y ofrece datos que no tienen la misma certeza y definición que otras coberturas territoriales como los usos del suelo, la vegetación o la geología. A nuestro entender, esta patología de nuestra disciplina tiene su origen en la diferencia entre Patrimonio Arqueológico y Registro Arqueológico. Si bien el primero tiene -o debería tenerunos límites claros y concisos, avalados por la Administración, el segundo puede presentar unos límites tenues y difusos, con cierta continuidad sobre el territorio.

Para paliar este problema y plasmar cartográficamente el registro arqueológico difuso, una de las operaciones de gestión de datos más interesantes que permiten los SIG en los trabajos de prospección es la generación de mapas de densidades. Mediante varios métodos de interpolación se producen mapas de isolíneas y coropletas que unen puntos con un mismo valor en cuanto al número de hallazgos (o cualquier otro parámetro). A lo largo del próximo apartado veremos varios ejemplos. En cualquier caso, previamente hay un intenso trabajo de campo y de gabinete ordenando los datos. En el caso de Pieza Redonda, la información recogida en campo se ha anotado en una tabla con unos apartados predeterminados, posteriormente se ha digitalizado en una hoja de cálculo y se ha volcado en una plataforma propia de los SIG, convirtiéndose así en la tabla de atributos de un archivo shape (.shp). A partir de este punto la versatilidad de los datos es muy amplia, ya que se pueden realizar mapas de todo tipo (dispersión, densidades,...) mediante diferentes operaciones 0 geoprocesamientos en función del software SIG utilizado (ArcMap, gvSIG, QGIS,..).

Por último, cuando hablamos de plasmaciones geográficas no podemos olvidar el peso analítico de la cartografía, de la fotografía aérea antigua y actual o de los sistemas LIDAR para identificar elementos, caracterizarlos y observar su pervivencia / ruptura a través del tiempo, más allá de constituir meras plataformas donde plasmar los resultados obtenidos en la inspección visual. En el caso concreto de Pieza Redonda, se han escrutado recursos existentes en la Diputación Foral de Álava y en Gobierno Vasco (muchos de ellos de libre acceso en red) desde los años 30 del siglo XX, que han facilitado enormemente tanto el propio desarrollo del trabajo de campo como el posterior análisis histórico regresivo.

\section{3.- RESULTADOS: EVOLUCIÓN DE LA OCUPA- CIÓN Y EXPLOTACIÓN DE PIEZA REDONDA}

Basándonos en la enorme diversidad de materiales y estructuras identificadas, contrastando dichos hallazgos con otro tipo de fuentes escrutadas (especialmente bibliográficas, documentales, orales y gráficas pasadas y actuales), y teniendo en cuenta el contexto arqueológico más próximo, estamos en disposición de ofrecer una síntesis del proceso histórico del complejo, que apoya nuestra defensa de la prospección superficial como técnica de análisis aun a falta de completar el documento arqueológico en futuras campañas con la interpretación del registro del subsuelo.

\subsection{Ocupación protohistórica}

Como se puede apreciar en la tabla 4, se ha documentado más de un millar de evidencias de carácter puntual. Un $90 \%$ de ellas han sido fragmentos de cerámica, de las cuales más de la mitad son de época protohistórica. La inmensa mayoría de la cerámica modelada del Bronce Final-Primera Edad de Hierro se sitúa en un sector muy concreto del área de estudio. Salvo algunos casos aislados y dispersos por otras zonas del yacimiento, la mayoría se sitúa en la mitad oriental del cerro principal, especialmente en su ladera sudoriental, entre la cota 470 y los 496 metros de la cima. Este espacio coincide con una zona intensamente erosionada y aparentemente con escasas posibilidades de albergar evidencias en el subsuelo.

Por el contrario, en el resto de la mitad oriental del cerro principal la presencia de cerámica protohistórica es muy limitada, aunque en este caso se trata de una zona con una vegetación más densa y, lógicamente, con una menor visibilidad. Como contrapartida, se ha constatado en varios perfiles de los caminos que en esta zona hay un mayor espesor del regolito por lo que la potencialidad arqueológica del subsuelo aumenta de forma considerable.

Dentro de este tipo de evidencias hemos diferenciado cerámica lisa, bruñida y decorada, aunque no se han separado cartográficamente ya que un mismo fragmento podría corresponderse con más de un tipo (por ejemplo, si una cerámica está decorada por una parte y el resto es lisa). Toda esta cerámica del Bronce Final-Primera Edad de Hierro ha sido fabricada a mano y podemos observar sin dificultad abundantes desgrasantes minerales, concretamente calcita (carbonato cálcico), de tamaños medios y grandes. En algunos casos existe decoración, especialmente digitaciones (8 ejemplares), pero también ungulaciones (3 ejemplares), incisiones (1 ejemplar) y relieve (1 ejemplar).

Entre el material de esta época también destaca la presencia de 6 fragmentos dispersos de molinos de mano barquiformes, que se localizan igualmente en la mitad oriental del cerro. Dada la naturaleza y tamaño de estas últimas evidencias es de suponer que no deberían haberse desplazado demasiado de posición desde su abandono. La proximidad de todos ellos -se localizan en dos grupos de tres fragmentos, con una distancia extrema 

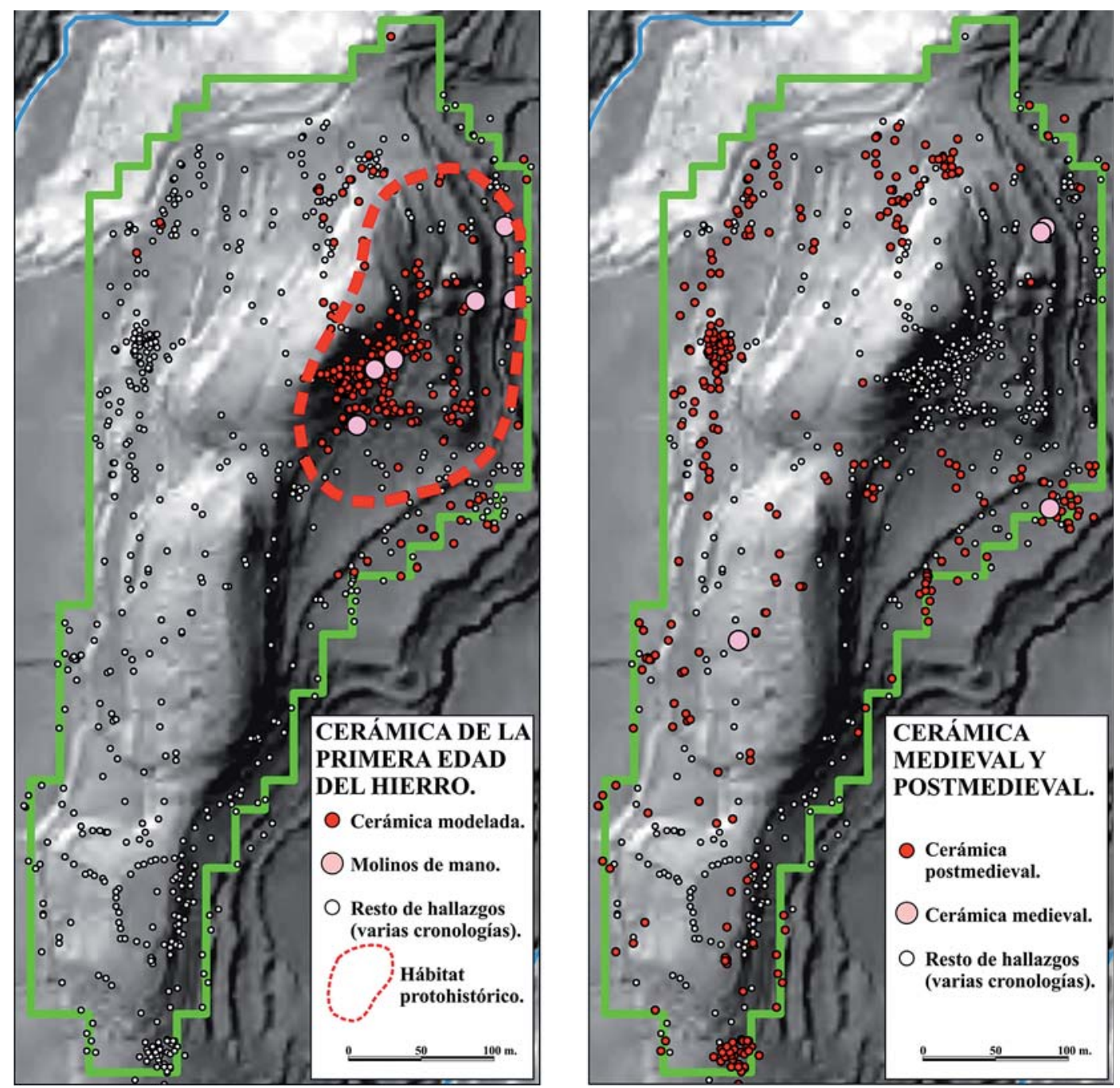

Fig. 4. Dispersión de hallazgos. Cerámica de la Primera Edad del Hierro y Cerámica Medieval y Postmedieval Dispersion findings. Early Iron Age Pottery and Medieval and Postmedieval Pottery.

entre las piezas de unos 170 metros- da consistencia a esta sospecha. De este modo, mediante el solapamiento cartográfico de la distribución de la cerámica del Bronce Final-Primera Edad del Hierro con la de los molinos de mano, proponemos que seguramente el hábitat de esta época debió ceñirse estrictamente a este sector.

El resto del material lítico lo constituyen otra docena de piezas muy fragmentadas entre pulimentos, alisadores y otros elementos indeterminados, cuya cronología puede ser más dudosa y diversa. En cualquier caso, la escasa presencia de industria lítica puede deberse, entre otras cosas, a su complicada visualización e identificación durante la inspección superficial.

¿Cómo podemos valorar la calidad potencial del registro del subsuelo a partir de los datos en superficie? Proponemos una vez más las consideraciones de Francisco Burillo Mozota, quien distingue cuatro categorías de yacimientos arqueológicos según el tipo de evidencias conservadas en superficie (2013: 28-29; también en BURILLO et al., 1993: fig. 6)
1. Yacimiento arqueológico cuyo contexto interno no ha sido alterado.

2. Yacimiento arqueológico en el que se han producido importantes variaciones de su contexto interno, pero sin que se modifique su situación.

3. Yacimiento arqueológico formado por materiales desplazados de su ubicación primitiva, pero con indicios suficientes como para determinar su ubicación original (a).

4. Hallazgo suelto o aislado formado por materiales carentes de todo contexto arqueológico con los que se pueda relacionar.

Según este esquema, nos encontraríamos -en el peor de los casos- ante la tercera opción, aunque tenemos indicios suficientes para pensar que pudiera conservarse parte del yacimiento no excesivamente alterado (primera y segunda opciones) en algunos sectores. De este modo, si se cumplen estas expectativas, en futuras campañas se podrían definir en el subsuelo algunas características del emplazamiento y su estructuración interna, así como com- 


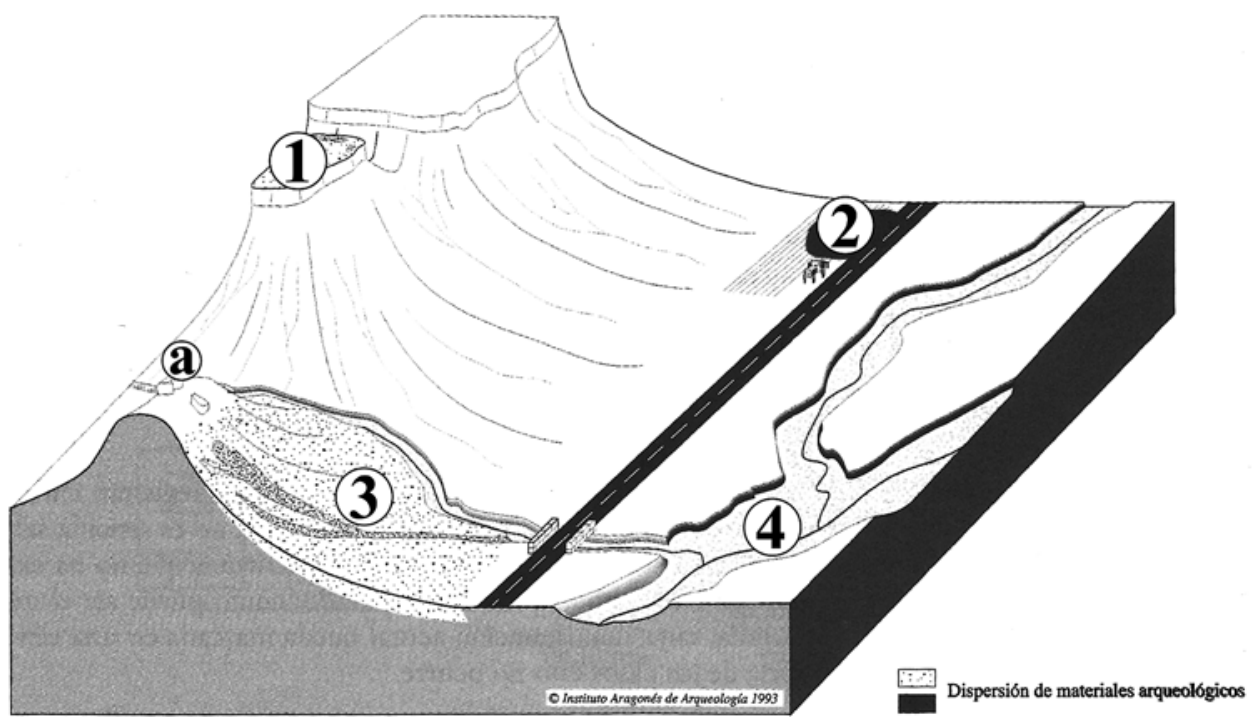

Fig. 5. Diagrama de categorías de yacimientos arqueológicos, en función de la calidad del registro (BURILLO et al., 1993: fig. 6) / Diagram of categories of archaeological sites, depending on the quality of the register. (BURILLO et al., 1993: fig. 6).

probar la concordancia con los datos de otros poblados de cronología similar estudiados en Navarra y La Rioja (CASTIELLA, 1977: 13-14):

- Cerros a poca altura sobre el entorno más o menos llano inmediato.

- Cerca de manantiales o en la unión de dos cursos de agua.

- El perfil de los cerros presenta uno o más escalones.

- La ordenación interna se adapta a la topografía local.

- Predominan las viviendas rectangulares con una compartimentación tripartita: vestíbulo, hogar despensa.

- También se reconocen viviendas de planta circular aunque son menos frecuentes y se asocian a un horizonte cultural anterior.

Ampliando el foco, Pieza Redonda se inserta en la red de yacimientos protohistóricos -especialmente del Hierro I o Hierro Antiguo- del Valle Medio del Ebro. Se trata de una densa malla y muy bien articulada, en la que la mayoría de los poblados apenas se muestran separados por 4 o 5 kilómetros. En un radio de apenas 13 kilómetros desde Pieza Redonda se localizan hasta 13 asentamientos. La razón por la que el conocimiento del poblamiento de esta época en este sector de Álava es bastante completo se debe fundamentalmente a las campañas de prospecciones sis-

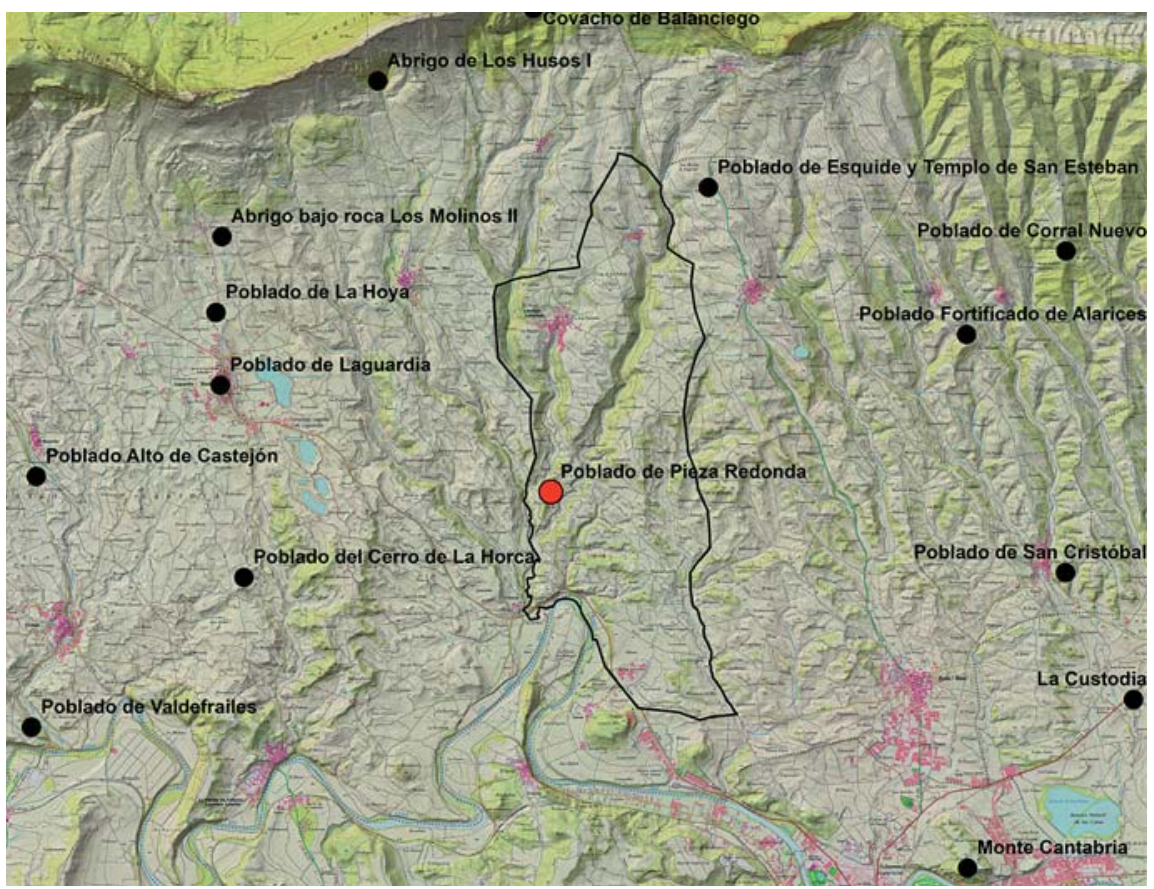

Fig. 6. Principales yacimientos de la Primera Edad del Hierro localizados en el entorno del Poblado de Pieza Redonda. En este mapa se ha otorgado el mismo peso a todos los asentamientos aunque, lógicamente, debió haber una jerarquía interna entre ellos / Main deposits of the Early Iron Age located in of the Village of Pieza Redonda. This map has given the same significance to all settlements though, logically, an internal hierarchy between them should have existed. temáticas llevadas a cabo por el Instituto Alavés de Arqueología durante décadas. Algunos de los yacimientos han sido excavados parcialmente, entre los que destacan La Hoya, La Custodia (Viana, Navarra), el Covacho de Balanciego y el Alto de Castejón. De hecho, es con este último poblado con el que Pieza Redonda presenta más paralelismos, tanto en el tipo de emplazamiento como en cronología (MARTíNEZ TORRECILLA et al., 2012: 115-121; MARTÍNEZ TORRECILLA, 2014: 110-112). 


\subsection{Abandono del Poblado y escasez de restos de época romana y medieval}

Teniendo en cuenta la cronología de los hallazgos, a partir de la segunda mitad del I Milenio a.C., no parece que el lugar siguiera ocupado, al menos no de forma permanente. Así lo atestigua la escasísima representación de cerámica de época celtibérica, con un solo fragmento. Parece que durante la Segunda Edad del Hierro hay una reestructuración del poblamiento en la zona, con menos centros pero con un urbanismo más organizado (La Hoya, La Custodia), que parece discurrir en paralelo a nuevas influencias desde la zona ibérica (PEÑALVER, 2008).

Todavía es más llamativa la ausencia total de material de época romana, a pesar del citado único fragmento de terra sigillata recogido en la prospección de 1994. Teniendo en cuenta las evidencias del poblamiento de época romana en la comarca (FILLOY y GIL, 2000: 3758) encontramos cierta densidad de asentamientos en las proximidades de Laguardia (La Iglesia/Las Pilas, El Cerrado, Corral de Tabiques,...) que realmente forman parte de un eje que se distribuye en dirección OSO-ENE, desde Baños de Ebro hacia El Pago de Esquide. Por otro lado, es lógico suponer que esta ruta se comunicaría transversalmente con el Ebro y con otras vías mucho más importantes situadas en su margen derecha, que unían Gracchurris, Calagurris, Vareia y Tritium. A menos de dos kilómetros del emplazamiento de Pieza Redonda se localiza, en el entorno del meandro del Ebro en Assa, una zona de alta densidad de evidencias romanas (El Campillar, Assa II, Viña Assa, Puente de Mantible,...) que nos ofrece indicios sólidos de dónde pudo situarse un importante nudo de comunicaciones.

Tampoco los restos muebles de época medieval son muchos, con apenas cinco fragmentos de cerámica común de pasta micácea, de lo que ha venido a denominarse Grupo V (SOLAUN, 2005). Sin embargo, en cuanto a la explotación del medio, comienzan a documentarse desde al menos el siglo XV ciertas actividades agrícolas que llevan aparejadas intensas transformaciones en el paisaje de Pieza Redonda, centralizadas desde Laguardia y Lanciego, por entonces aldea sujeta a la jurisdicción de aquella. Por ejemplo, la presencia de un amplio regadío que vertebra y organiza el aprovechamiento agropecuario (zonas potenciales de regadío en cotas inferiores; secano y pastoreo en las zonas altas).

\subsection{La explotación de Pieza Redonda en los pe- riodos finimedieval y moderno}

Es a partir de la Edad Moderna cuando el número de evidencias vuelve a dispararse, con más de 400 fragmentos entre cerámica doméstica y cerámica constructiva. El patrón de distribución es sensiblemente diferente al detectado en las evidencias protohistóricas, con una vinculación muy clara con la caminería que delimita y rodea el yacimiento por todo su perímetro, entre las cotas 450 y 470 metros. En la cerámica de la Edad Moderna las formas y tipos se complejizan, hallándose cerámica común oxidante, loza popular vasca y, sobre todo, cerámica vidriada. Asimismo, se documenta cerámica constructiva (teja, ladrillo y azulejo). Y también se localizan otras evidencias con una mayor impronta en el paisaje, pero con unas dificultades propias en cuanto a su interpretación, que incluimos cautelarmente y de forma genérica muy al final de la Edad Media o ya en época postmedieval aunque bien, desde el punto de vista cronológico, pudieran hundir sus raíces más profundamente.

El área comprendida entre las localidades de Cripán, Viñaspre y Lanciego ha sido tradicionalmente lugar de regadío, como tantas otras zonas de Rioja Alavesa (AGUAYO, 1999; PALACIOS y RODRÍGUEZ, 2004), basado en la captación artificial de aguas en los arroyos que descienden en sentido Norte-Sur desde los nacederos de la Sierra de Cantabria hacia el Ebro. En la jurisdicción de Lanciego podemos documentar desde la Baja Edad Media y Edad Moderna los sistemas hídricos de Ardachal, Vallarmén-Valvariga o Alcalde, siempre sobre el arroyo Vallarmén, y la regadera de Vadillo sobre el curso del mismo nombre, especialmente interesante en su relación con el yacimiento de Pieza Redonda que nos ocupa.

En este último caso, la toma de agua se ubica muy cerca del núcleo de Cripán (a unos 100 metros aguas arriba de la carretera de Cripán a Lanciego), dentro de su jurisdicción, tomando el agua actualmente sin presa que cruce el arroyo Vadillo de lado a lado, sólo con un canal paralelo al curso con una cerraja. Las aguas canalizadas se dirigían al núcleo de Lanciego y, después de atravesarlo, siguen discurriendo en dirección sur hasta los términos de El Alto de la Paloma, Pieza Redonda, El Somo - El Horcajo. Es importante resaltar por tanto que además de su función en la agricultura irrigada de la zona, esta regadera sirvió también para el abastecimiento de los vecinos de Lanciego. Es un aprovechamiento intenso que requiere una potente gestión concejil de cara tanto a la defensa del bien común frente a otros intereses (por ejemplo, las pugnas con Cripán por la cantidad de agua) como en la propia vigilancia y distribución "interna" del caudal que llegaba a las diferentes casas y heredades.

Esta complejidad se comprueba en una referencia documental de 1452 (recogida en AGUAYO, 1999: 199), con el sistema ya funcionando desde hace tiempo. Lanciego poseía el dominio y la gestión de las aguas de la regadera, pese a "nacer" fuera de su territorio jurisdiccional inmediato. El caudal del canal artificial estaba determinado por lo que se denomina ojal, es decir, una abertura de diámetro determinado y pactado entre las poblaciones de Lanciego y Cripán, y oficializado a través de la sanción de la Chancillería Real. El volumen de agua no recogido seguía circulando por el cauce natural del arroyo Vadillo para, entre otras cosas, alimentar un molino harinero. A cambio de esta apropiación, el concejo de Lanciego se comprometía a mantener periódicamente su estructura para aprovechar al máximo el agua. 


\begin{tabular}{|c|c|c|c|}
\hline & $\begin{array}{l}\text { Regadera } \\
\text { Excavada }\end{array}$ & Cajeada en Piedra & Cemento \\
\hline $\begin{array}{l}\text { Unidad } \\
\text { Prospección }\end{array}$ & D015 & $\begin{array}{lll}\text { E056; } & \text { F022; H012; } \\
\text { l003; } & \text { I013; L081; } \\
\text { M041; } & \text { O008; } & 003 ; \\
\text { Q019? }\end{array}$ & $\begin{array}{lll}\text { E034; } & \text { F005; } & \text { G001; } \\
\text { G011; } & \text { H011; I010; } \\
\text { J016; } & \text { K016; L093; } \\
\text { M053; } & \text { N037; } & 032 ; \\
\text { P004; } & \text { P017; } & \text { Q012; } \\
\text { Q020; } & \text { Q025 }\end{array}$ \\
\hline
\end{tabular}

Tabla 6: Relación de Unidades de Prospección según su tipología constructiva. La Q019 presenta, en principio, cajeado de piedra, pero su identificación está dificultada por la amortización tras su abandono / Survey Units List by type of construction. The Q019 has, in principle, stone recess, but its identification is hampered by the depreciation after abandonment.

Como ya hemos avanzado, las canalizaciones hídricas en general y las regaderas en particular, suelen presentar una enorme profundidad histórica que se ve acompañada no obstante de continuos cambios morfotecnológicos. Curiosamente, la razón principal para explicar tan larga duración consiste en su "sencillez" técnica: el agua corre por gravedad, y precisamente este hecho origina un eje estable entre el punto de origen, el espacio intermedio (área de uso) y el final. Los aprovechamientos hídricos se ubican en el propio recorrido del agua o a una cota menor, pero por encima del canal el aprovechamiento es prácticamente inexistente (BARCELÓ, 1989). De esta forma, se generaliza el uso continuado y acumulativo de un circuito frente a la complejidad de crear nuevos espacios, a través de sucesivos paisajes y contextos históricos. Ello provoca una riqueza de registro diacrónico pero, al mismo tiempo, las estructuras más actuales pueden hacer desaparecer las anteriores.

En el yacimiento de Pieza Redonda se conservan numerosos restos materiales de estas prácticas históricas de regadío. Contamos con tramos de canales artificiales excavados en el terreno, cajeados en piedra o con encofrado de cemento contemporáneo (a veces coexistiendo), lo que da muestra de un uso reiterado hasta periodos recientes, pero también existen otros elementos característicos como puntos de distribución y reparto, chozos o guardaviñas relacionados con el depósito de aperos de labranza, vigilancia del sistema hídrico y resguardo de personas, e innumerables muretes de aterrazamiento que delimitan heredades agrícolas.

Son dos las líneas principales de agua conectadas con el regadío de Vadillo; una primera que discurre por el lado oriental del yacimiento, siguiendo la isolínea de cota 460 metros y creando un área de riego por gravedad hacia el sur y este; y otra que recorre el sector occidental a una altitud, dando lugar a un espacio irrigado hacia el oeste y suroeste. La presencia de cajas de cemento en varios tramos del recorrido denuncia un uso muy reciente, pero existen restos más antiguos de paredes de mampostería, sectores excavados en el terreno sin obra e incluso puntos de distribución ya abandonados que nos remiten a tiempos anteriores.
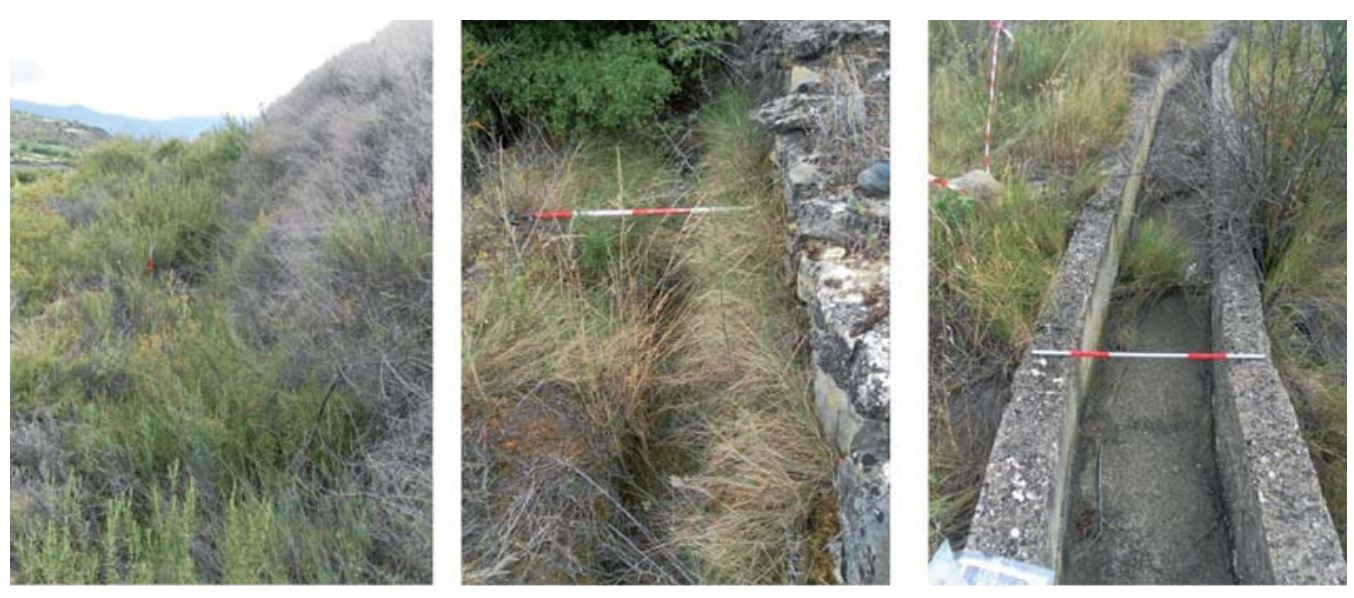

Fig. 7. Ejemplo de las tipologías mostradas anteriormente: tramos excavados (D015), delimitados en mampostería (Q003) y cajeados en cemento (E034) / Example of the types shown above: excavated sections (D015), delimited in masonry (Q003) and recesses in concrete (E034).
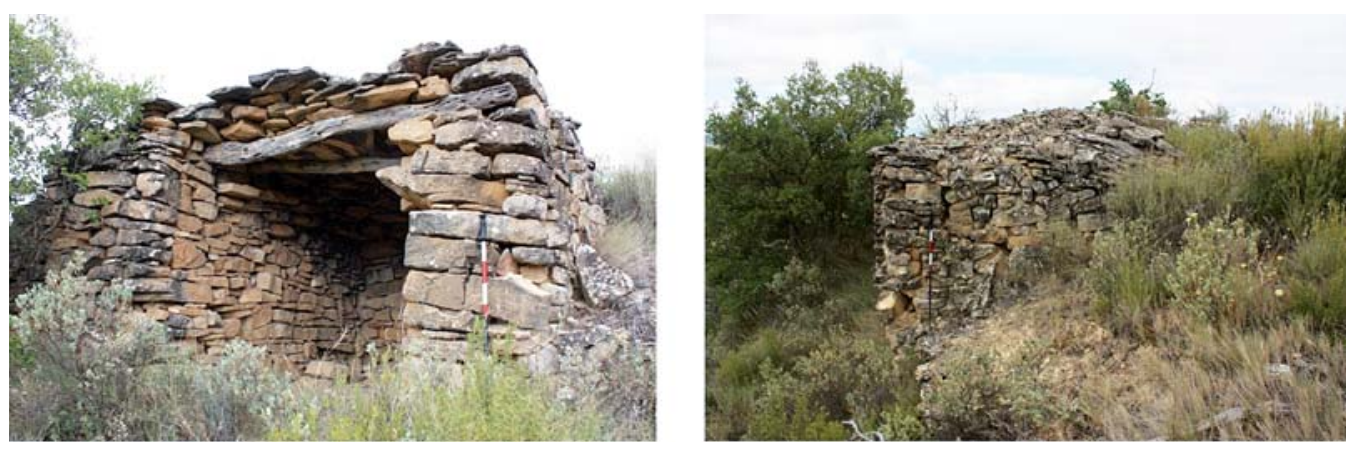

Fig. 8. Chozo (UP número F011) ubicado junto a la regadera oriental de Pieza Redonda / Chozo (UP number F011) next to the eastern irrigation system of Pieza Redonda. 
También es destacable la presencia de chozos o guardaviñas (fábrica de mampostería regularizada en hiladas y aparejada en seco cuya cubierta se soluciona en una cúpula por aproximación de hiladas) junto a las canalizaciones, ligeramente elevados sobre ellas para no entorpecer la irrigación. Creemos que estas arquitecturas responderían a necesidades más relacionadas con el refugio ante las inclemencias del tiempo y el depósito de aperos de labranza, sin olvidar un cierto control sobre el cauce de riego.

Por encima de la curva de nivel de los 460 metros también existen indicios de agricultura irrigada, por ejemplo viñedos cultivados hoy día gracias al actual sistema de re- gadío soterrado que, por cierto, coincide en ocasiones con la regadera de Vadillo tradicional. Sin embargo, queremos llamar la atención sobre una nueva línea de agua detectada en varios puntos de un corto tramo del lado sudoriental del cerro, a una altura aproximada de 470 metros, que aparece delimitada por muretes de mampostería e incluso trabajando la roca natural en desarrollo vertical, y sin presentar una evolución reciente hacia el cemento. El abandono de este circuito se produjo por tanto antes que las regaderas inferiores, pero por el momento no sabemos cuánto antes ni durante cuánto tiempo funcionó esta canalización; no sin realizar una intervención arqueológica sobre los rellenos de amortización del elemento.

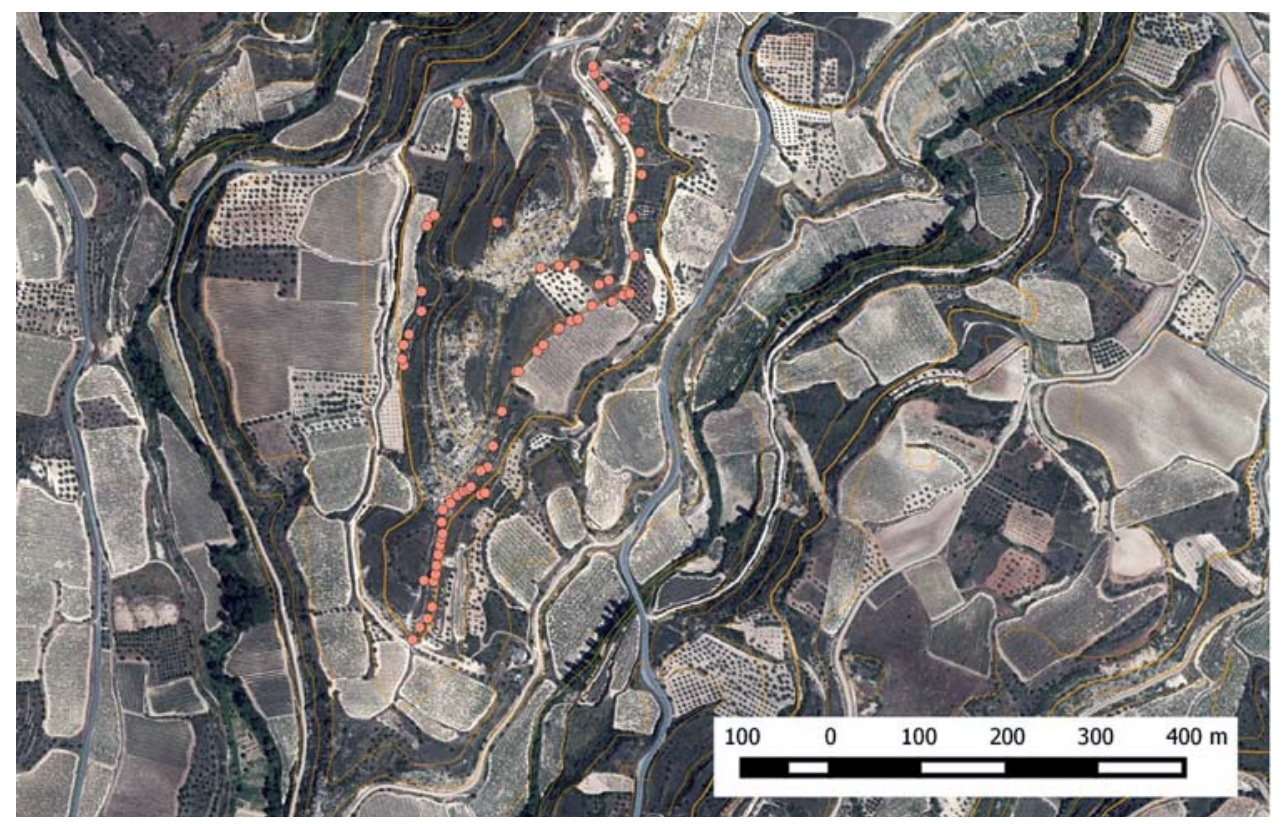

Fig. 9. Puntos Georreferenciados de las distintas Unidades de Prospección referidas a estructuras de regadío documentadas durante la prospección, permitiendo la reconstrucción del diseño general / Georeferenced Points of different Survey Units regarding irrigation structures documented during the survey, allowing the reconstruction of the overall design.

\begin{tabular}{|c|c|c|c|c|c|c|c|}
\hline A & B & C & D & $E$ & F & G & H \\
\hline $\begin{array}{l}A 001 \\
A 005 \\
A 012\end{array}$ & $\begin{array}{l}\text { B006 } \\
\text { B007 } \\
\text { B008 }\end{array}$ & $\begin{array}{l}\text { C003 } \\
\text { C004 } \\
\text { C005 } \\
\text { C019 } \\
\text { C021 }\end{array}$ & $\begin{array}{l}\text { D003 } \\
\text { D004 } \\
\text { D005 } \\
\text { D007 } \\
\text { D008 } \\
\text { D012 } \\
\text { D014 } \\
\text { D056 }\end{array}$ & $\begin{array}{l}\text { E036 } \\
\text { E047 } \\
\text { E051 } \\
\text { E052 } \\
\text { E054 }\end{array}$ & $\begin{array}{l}\text { F007 } \\
\text { F009 } \\
\text { F012 }\end{array}$ & $\begin{array}{l}\text { G004 } \\
\text { G005 } \\
\text { G007 } \\
\text { G008 } \\
\text { G012 } \\
\text { G014 }\end{array}$ & $\begin{array}{l}\text { H001 } \\
\text { H004 } \\
\text { H006 } \\
\text { H009 } \\
\text { H013 } \\
\text { H014 }\end{array}$ \\
\hline I & $\mathbf{J}$ & K & $\mathbf{M}$ & $\mathbf{N}$ & 0 & $\mathbf{P}$ & $\mathbf{Q}$ \\
\hline $\begin{array}{l}1001 \\
1002 \\
1006 \\
1007 \\
1008 \\
1011\end{array}$ & $\begin{array}{c}\text { J001 } \\
\text { J003 } \\
\text { J005 } \\
\text { J014 } \\
\text { J015 } \\
\text { J037 }\end{array}$ & $\begin{array}{l}\text { K014 } \\
\text { K028 }\end{array}$ & $\begin{array}{l}\text { M004 } \\
\text { M005 } \\
\text { M006 }\end{array}$ & $\begin{array}{l}\text { N018 } \\
\text { N026 } \\
\text { N029 } \\
\text { N030 }\end{array}$ & $\begin{array}{l}\text { O019 } \\
\text { O023 } \\
\text { O025 }\end{array}$ & $\begin{array}{l}\text { P001 } \\
\text { P005 } \\
\text { P012 } \\
\text { P015 }\end{array}$ & $\begin{array}{l}\text { Q001 } \\
\text { Q002 } \\
\text { Q004 } \\
\text { Q010 } \\
\text { Q011 } \\
\text { Q013 } \\
\text { Q014 } \\
\text { Q017 } \\
\text { Q018 }\end{array}$ \\
\hline
\end{tabular}

Tabla 7: Listado de Unidades de Prospección, distribuidas por transectos, referidos a estructuras murarias identificadas en el yacimiento / List of Survey Units distributed by transects, referring to wall structures identified at the site. 
Parte de los muros localizados en la prospección superficial están obviamente relacionados con los sistemas de regadío, conformando muretes de delimitación y aterrazamiento para heredades de cultivo. Pero también había que tener en cuenta terrenos de secano, pastizales propios de actividades ganaderas y, por supuesto, la posibilidad de identificación de restos asignables a la población protohistórica. En contra contábamos con un elevado número de hallazgos (184 registros o puntos georreferenciados correspondientes a 76 Unidades de Prospección distintas) y la, en principio, semejanza constructiva: piedra local aparejada en bloques de mampostería apenas desbastados en seco, es decir, sin morteros de cal.

Por lo tanto, y es una de las limitaciones ya anunciadas en el apartado metodológico, se hizo necesario un reconocimiento posterior más exhaustivo, de carácter tipológico, que tendrá continuación en posteriores campañas con la realización de algunos sondeos de control y limpieza de los paramentos en algunos puntos para dar consistencia a un estudio cronotipológico.

\section{4. Época contemporánea: la impronta de las Guerras Carlistas y las últimas transformaciones traumáticas}

En la Edad Contemporánea (un $28 \%$ sobre el total de la cerámica documentada), junto a los repertorios de cerámica común oxidante, loza popular vasca y cerámica vidriada aparece también la porcelana, y en el tipo constructivo se repiten las formas de teja, ladrillo y azulejo. La mayoría de estas evidencias se localizan en la mitad occidental de la zona de estudio, en cotas bajas. Quizás haya que relacionar su presencia con escombreras en las cunetas, rellenado de fincas, etc. Se ha comprobado si la presencia de tejas está asociada con las regaderas como elemento accesible y versátil, que facilitaría la propagación del riego, pero esta correlación ciertamente no se produce.

Como peculiaridad significativa hemos de apuntar la presencia de un pequeño fragmento de proyectil de artillería; concretamente, formaba parte del cuello del mismo, entre el inicio de la cabeza cilíndrico-ojival y el cuerpo. El material de hierro fundido guarda en su cara interior las marcas en donde estaba colocado el bote de metralla, de zinc o plancha de hierro, conteniendo en su interior las balas de plomo esféricas unidas con azufre fundido. Continuando en la cara interna, tenemos el inicio del hueco de un tubo que viene a ser el lugar donde se colocaba la espoleta de accionamiento de la carga. En la parte externa se aprecia la inscripción "F de T" / "1874", haciendo alusión al lugar (Fábrica de Trubia, Asturias) y año de fabricación.

Estos datos nos permiten contextualizar el proyectil en la Tercera Guerra Carlista (1872-1876). Desde noviembre de 1873, el núcleo estratégico de Laguardia había sido ocupado por tropas carlistas. Los intereses de ambos bandos se centraban en el control de la comarca y el corredor del Ebro desde Logroño hasta Miranda de Ebro, por lo que durante el año 1874 se produjeron varios cambios de mano en el control de la villa y su entorno en un corto lapso de tiempo, hasta culminar el paso definitivo a manos del ejército liberal en octubre (CUERPO DEL ESTADO MAYOR DEL EJÉRCITO, 1880). La marcha del ejército liberal al mando del general Manuel de la Serna sobre Laguardia desde Logroño tuvo una fuerte oposición carlista en el desfiladero y las posiciones de Assa, junto al río Ebro, distante apenas un kilómetro al sur de Pieza Redonda. Y es precisamente en este intercambio de fuego de artillería cuando debemos documentar el hallazgo puntual, que perteneció con toda seguridad al ejército liberal que trataba de rendir las posiciones carlistas del entorno de Assa (SÁNCHEZ, 1991).

Concluiremos el recorrido histórico recordando que este cerro y sus alrededores han sufrido durante el último siglo importantes transformaciones en los usos del suelo y del paisaje, fundamentalmente debidos al abandono de aprovechamientos tradicionales, cierta reestructuración del parcelario rústico y, sobre todo, por el cambio de la explotación tradicional del olivar por el casi monocultivo intensivo del viñedo. Durante esta metamorfosis es de suponer que muchas de estas estructuras fueron afectadas en mayor o menor medida, así como el registro arqueológico del subsuelo (muchas de las piezas cerámicas presentan profundas incisiones del arado). De hecho, entre los hallazgos de esta época destaca un fragmento de arado mecánico actual que delata la intensidad de este impacto.

\section{4.- CONCLUSIONES}

En primer lugar, creemos haber dejado meridianamente claro a lo largo del apartado anterior el valor de la prospección superficial como herramienta arqueológica para generar conocimiento histórico, especialmente en combinación con otro tipo de fuentes (transdisciplinariedad). Si bien el objetivo inicial estaba básicamente enfocado a la caracterización del por entonces supuesto poblado protohistórico que los escasos indicios anteriores daban a entender, la intervención ha puesto de manifiesto la conveniencia de acercarse al registro material de forma territorial, diacrónica y holística. Sólo así se puede interpretar el Paisaje (y concretamente la porción de él que constituya nuestro objeto de estudio) de forma transversal, como una acumulación estratificada de evidencias con mayor o menor grado de impacto que, en todo caso, es la síntesis de la compleja relación entre el ser humano y el medio.

En segundo lugar, es innegable que la delimitación y primera caracterización del yacimiento o, quizás mejor, de aquellas partes del yacimiento más interesantes para el investigador, es sumamente eficaz en el marco de una investigación de mayor recorrido, siquiera como una actuación previa imprescindible antes de cualquier otra labor más destructiva, invasiva y costosa, sobre un yacimiento arqueológico. En el caso de Pieza Redonda, disponemos ahora de una serie de argumentos sólidos que nos ayudan a definir más claramente el hábitat protohistórico y su evolución posterior, contextualizando de la mejor manera posible las futuras actividades de excavación. 

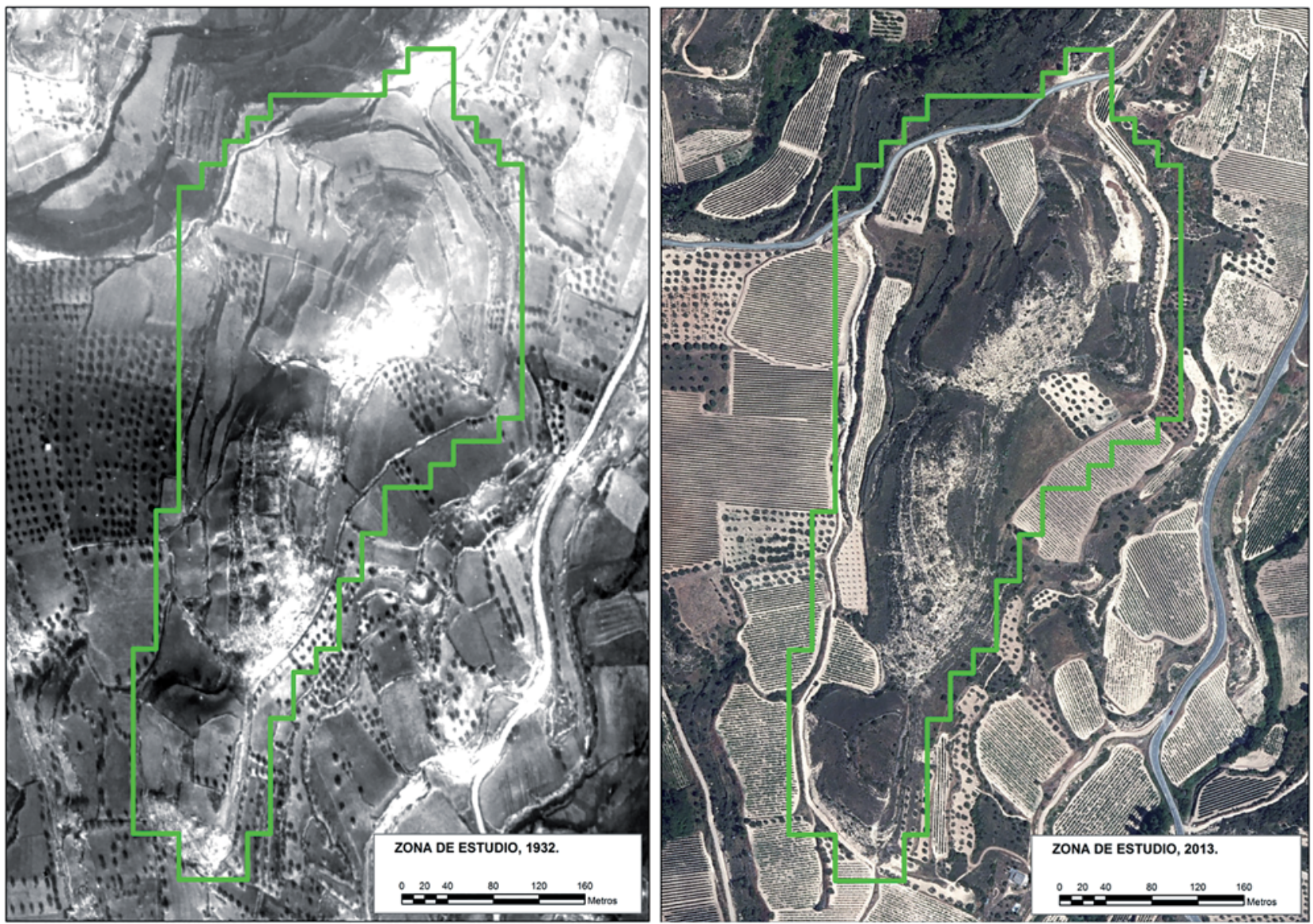

Fig. 10. La zona de estudio en dos momentos. Comparación entre una fotografía aérea de 1932 (Diputación Foral de Álava) y una ortofoto actual (Gobierno Vasco) / The study area in two stages. Comparison between an aerial photograph of 1932 (Diputación Foral de Álava) and current orthophoto (Basque Government).

En tercer lugar haremos mención a la cuestión patrimonial, especialmente a la consideración legal y a un grado de protección que además es importante en relación a los propios recursos futuros de investigación, toda vez que su consideración como figura monumental puede suponer la entrada en ciertos circuitos de visibilidad que generan nuevas posibilidades de conocimiento, recuperación, difusión, etc. La campaña de 2014 ha aportado información suficiente como para que el yacimiento de Pieza Redonda se dote en un futuro de un régimen de protección adaptado a sus características y nueva delimitación espacial, algo de lo que en la actualidad carece totalmente.

No obstante, inmediatamente surgen varias consideraciones que deberán ser tenidas en cuenta en futuras actividades arqueológicas: (1) si bien el poblado protohistórico debió estar situado en el cuadrante sudoriental del cerro principal, es plausible que las estructuras defensivas -si las hubiera- rodearan toda la mitad oriental del altozano, con espacios vacíos intercalados, no necesariamente ocupados por viviendas. En la campaña de prospección de 2014 se han localizado estructuras que requieren un estudio pormenorizado de sus rasgos morfotécnicos y métricos que permitan adscribirlos cronoló- gicamente. Para ello es necesario partir de algunos casos concretos datados, a modo de fósiles directores. Y para la datación hay que basarse en datos de tipo arqueométrico y estratigráfico, realizando una o varias trincheras que corten perpendicularmente las curvas de nivel, de forma similar a como se ha realizado en el Alto de Castejón (Navaridas) en la campaña de 2013 (MARTíNEZ TORRECILLA, 2014: 110-112). (2) Más allá del contexto protohistórico actualmente acotado, existieron elementos que formaron parte de su vida y que permanecen todavía silenciosos en el registro arqueológico. Entre ellos, la necrópolis o las vías de comunicación que debieron relacionar esa densa red de poblamiento que mencionábamos anteriormente. Sería interesante acercarse a estos aspectos desde una nueva actuación de inspección visual del territorio, de carácter más extensivo y selectivo. (3) Por último, Pieza Redonda posee una significación histórica que va más allá de su (¿primera?) ocupación durante el primer milenio a.C., pero el peso de este asentamiento puede suponer a efectos prácticos el establecimiento de una "cronología predominante" que haga olvidar lo ocurrido en ese espacio durante los siguientes 2.500 años. El remedio es sencillo, y consiste en poner en valor el conjunto de forma global. 

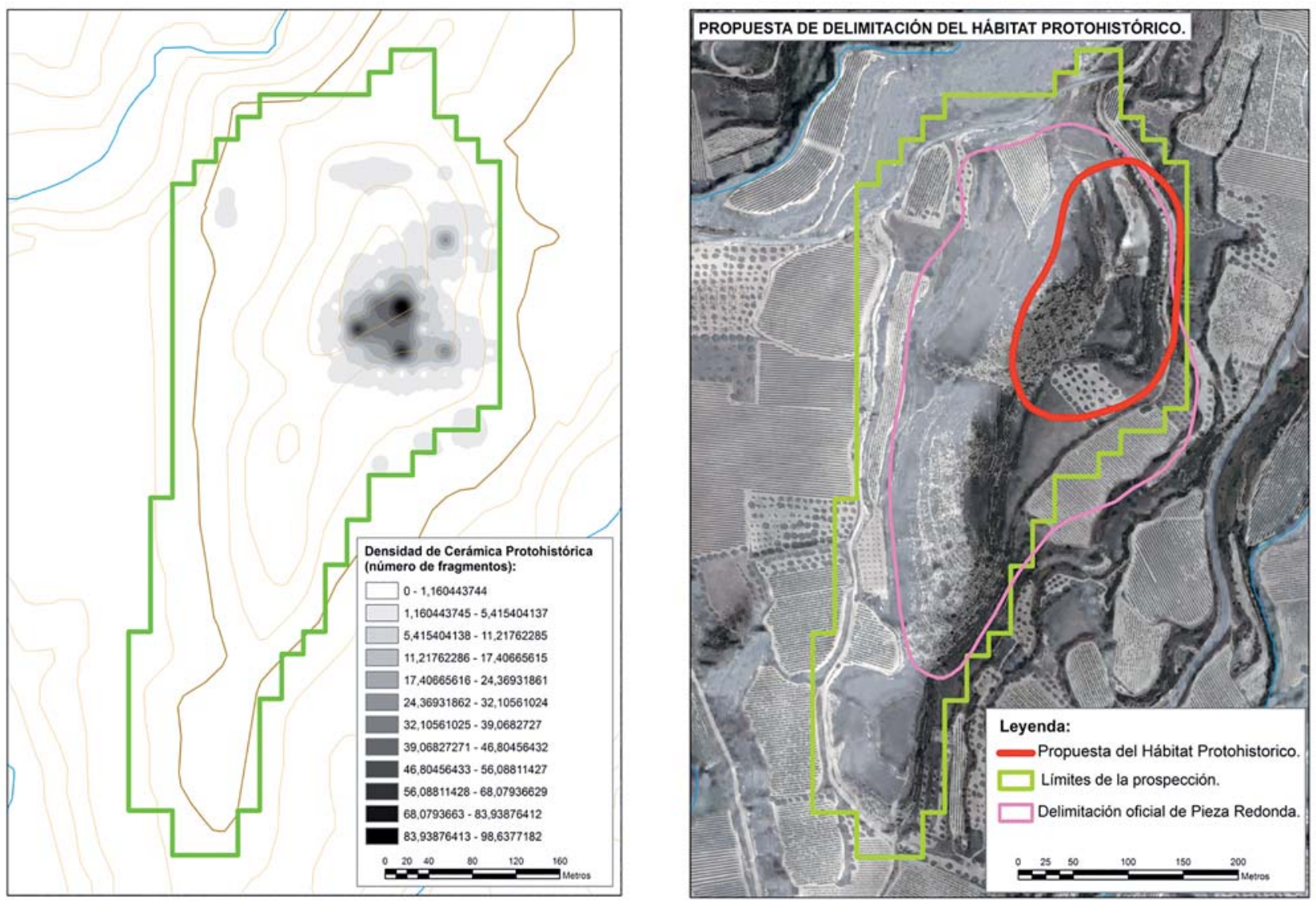

Fig. 11. Propuesta de delimitación del hábitat del Bronce Final-Primera Edad del Hierro a partir de la densidad de evidencias de esa época / Proposed delimitation of Late Bronze-Early Iron Age habitat, from the density of evidence of that time.

\section{BIBLIOGRAFÍA}

\section{AGUAYO CAMPO, T.}

1999 El regadío tradicional en Rioja Alavesa: su contexto socioeconómico. Diputación Foral de Álava. Vitoria-Gasteiz.

\section{ALBERTOS FIRMAT, M.L.}

1970 Álava Prerromana y Romana. Estudios de Arqueología Alavesa 4, 107-234.

BAENA, J., BLASCO, C. y QUESADA, F. (eds.)

1999 Los SIG y el Análisis Espacial en Arqueología. Servicio de Publicaciones de la UAM. Madrid.

\section{BALDEÓN IÑIGO, A. y SÁNCHEZ SIERRA, M.J.}

2006 Depósitos en hoyo de la Edad del Bronce en Álava. Santa María de Estarrona (Estarrona, Vitoria-Gasteiz), Peracho y Alto Viñaspre (Kripan). Diputación Foral de Álava. VitoriaGasteiz.

BANNING, E.B.

2002 Archaeological survey. Kluwer Academic / Plenum Publishers. New York.
BARCELÓ PERELLÓ, M.

1989 El diseño de espacios irrigados en Al-Andalus: un enunciado de principios generals, en CARA BARRIONUEVO, L. El agua en las zonas áridas: Arqueología e Historia. I coloquio de Historia y Medio Físico. 15-40. Instituto de Estudios Almerienses. Almería.

BARRACHINA, C.P. y ESCRIBANO, S.

2012 Las producciones cerámicas vascas de época moderna: un caso práctico de arqueología histórica, Promontoria Monográfica 16. JIA 2011(I), 219-224.Universidade do Algarve. Faro.

BINFORD, L.R

1998 En busca del pasado. Ed. Crítica. Barcelona.

BORJA SIMÓN, J.A.

1993 Identificación y análisis de procesos postdeposicionales en yacimientos del primer milenio a.C. en la Cuenca de Pamplona. Arqueología Espacial 16-17, 191-205.

BUREL F. y BAUDRY J.

2002 Ecología del paisaje. Ed. Mundi-Prensa. Madrid. 
BURILLO MOZOTA, F.

2013 La prospección de superficie, en GARCÍA DíEZ, M. y ZAPATA PEÑA, L. (eds.). Métodos y técnicas de análisis y estudio en Arqueología Prehistórica. De lo técnico a la reconstrucción de los grupos humanos. 15-38. Servicio de Publicaciones de la Universidad del País Vasco. Bilbao.

\section{BUTZER, K.W.}

1989 Arqueología. Una ecología del hombre. Ed. Bellaterra. Barcelona.

CAMBI, F.

2001 Prospección arqueológica, en FRANCOVICH R. y MANACORCA D., Diccionario de Arqueología. 301-308. Ed. Crítica. Barcelona.

CAMBI, F. y TERRENATO, N.

1994 Introduzione all'archeologia dei paesaggi. Roma.

\section{CARANDINI, A.}

1997 Historias en la tierra. Manual de excavación arqueológica. Ed. Crítica. Barcelona.

\section{CASTIELLA RODRÍGUEZ, A.}

1977 La Edad del Hierro en Navarra y Rioja. Institución Príncipe de Viana. CSIC. Pamplona.

1986 Nuevos yacimientos protohistóricos en Navarra. Trabajos de Arqueología Navarra 5, 133-173.

\section{CASTIELLA RODRÍGUEZ, A. et al.}

1999 Poblamiento y territorialidad en la Cuenca de Pamplona: una visión arqueológica. Cuadernos de Arqueología de la Universidad de Navarra 7, vol. I y II. Pamplona.

CATTANI M. y FIORINI A.

2004 Topologia: identificazione, significato e valenza nella ricerca archeologica. Archeologia e Calcolatori 15, 317-340.

\section{CHAPA BRUNET, T. et al.}

2003 Propuesta metodológica para una prospección arqueológica sistemática: el caso del Guadiana Menor (Jaén, España). Trabajos de Prehistoria 60 (1), 11-34.

CONOLLY, J. y LAKE, M.

2009 Sistemas de información geográfica aplicados a la arqueología. Ed. Bellaterra. Barcelona.

\section{CRIADO BOADO, F.}

1993 Límites y posibilidades de la arqueología del paisaje. SPAL 2, 9-55.

\section{CUERPO DEL ESTADO MAYOR DEL EJÉRCITO}

1880 Narración Militar de la Guerra Carlista de 1869 a 1876. Imprenta y litografía del depósito de la Guerra. Madrid.

DE LATORRE Y LEÓN, M.

1875 Tratado Elemental de Fortificación de Campaña, con Nociones de la Permanente y del Material de Guerra. Valladolid.
DIEZ MARTÍN, F.

2013 La arqueología del paisaje: Análisis macro y meso-espacial, en GARCÍA DÍEZ M. y ZAPATA PEÑA, L. (eds.). Métodos y técnicas de análisis y estudio en Arqueología Prehistórica. De lo técnico a la reconstrucción de los grupos humanos. 219-243. Servicio de Publicaciones de la Universidad del País Vasco. Bilbao.

DOMINGO, I., BURKE, H. y SMITH, C.

2007 Manual de campo del arqueólogo. Ed. Ariel. Barcelona.

ENCISO VIANA, E. y CANTERA ORIVE, J.

1967 Catálogo Monumental de la Diócesis de Vitoria. Tomo I: Rioja Alavesa. Diputación Foral de Álava. Vitoria-Gasteiz.

\section{ESCRIBANO RUIZ, S.}

2012 El registro cerámico del País Vasco: Araba y Bizkaia, ss. XIV al XVII. Retrospectiva heurística, en Estudiar el pasado: aspectos metodológicos de la investigación en Ciencias de la Antigüedad y de la Edad Media. 231-236. BARS2412. Oxford.

EVE

1993 Mapa Geológico del País Vasco, a escala 1:25.000. Hoja 170-IV/203-II, Laguardia. Bilbao.

FAIRCLOUGH, G.

2002 Archaeologists and the European Landscape Convention, en FAIRCLOUGH, G. y RIPPON, S. (eds.). Europe's Cultural Landscape: archaeologists and the managemenet of change. 25-57. EAC Occasional Paper 2. Bruselas.

FERNÁNDEZ CACHO, S.

2008 Patrimonio Arqueológico y Planificación Territorial. Estrategias de Gestión para Andalucía. Universidad de Sevilla.

FERNÁNDEZ MARTÍNEZ, V.M.

1989 Teoría y método de la arqueología. Editorial Síntesis. Madrid.

FILLOY NIEVA, I. y GIL ZUBILLAGA, E.

2000 La romanización en Álava. Catálogo de la exposición permanente sobre Álava en época romana en el Museo de Arqueología de Álava, Vitoria-Gasteiz.

FRANCO PÉREZ, J.

2007 Nuevas propuestas de prospección arqueológica en la región cantábrica. Territorio, sociedad y poder 2, 37-52.

\section{GARCÍA SANJUÁN, L.}

2005 Introducción al reconocimiento y análisis arqueológico del territorio. Editorial Ariel. Barcelona.

\section{GIL ZUBILLAGA, E. y FILLOY NIEVA, I.}

1988 Estudio arqueológico de los precedentes del poblamiento en torno a Vitoria-Gasteiz (Bronce Final-Edad del Hierro-Romanización). Estudios de Arqueología Alavesa 16, 445-530.

\section{GOBIERNO VASCO}

1992 Ley 7/1990, de 3 de julio, de Patrimonio Cultural Vasco. Vitoria-Gasteiz. 
GONZÁLEZ SALAZAR, J.A.

1986 Cuadernos de Toponimia Alavesa 3. Rioja Alavesa. Diputación Foral de Álava. Vitoria-Gasteiz.

HERNÁNDEZ VERA, J.A.

1982 Las ruinas de Inestrillas. Estudio arqueológico. Aguilar del Río Alhama, La Rioja. Instituto de Estudios Riojanos. Logroño.

HODDER, I. y ORTON, C.

1990 Análisis espacial en arqueología. Ed. Crítica. Barcelona.

IÑIGUEZ HERRERO, J. et al.

1980 Mapa de suelos de Álava. Escala 1:200.000. Diputación Foral de Álava. Vitoria.

IRANZO GARCÍA, E.

2010 El paisaje como patrimonio rural. Propuesta de una sistemática integrada para el análisis de los paisajes valencianos. Universitat de València. Valencia.

IRIARTE CHIAPUSSO, M.J.

2002 Antropización del paisaje y economía de producción entre los siglos XV y IV a.C. El entorno vegetal del yacimiento de La Hoya (Laguardia-Álava). Estudios de Arqueología Alavesa 19, 164-190.

\section{LLANOS ORTIZ DE LANDALUZE, A.}

1974 Urbanismo y Arquitectura en poblados alaveses de la Edad del Hierro. EAA 6, 101-146.

1975 Algunas consideraciones para la localización de establecimientos pre y protohistóricos. Kobie 6, 127-130.

1990 La Edad del Hierro y sus precedentes, en Álava y Navarra. Munibe Antropología-Arkeologia 42, 167-179.

1995 El poblamiento celtibérico en el Alto Valle del Ebro. III Simposio sobre los celtíberos: Poblamiento celtibérico. 289328. Institución Fernando el Católico. Zaragoza

\section{LLANOS ORTIZ DE LANDALUZE, A. (coord.)}

1987 Carta Arqueológica de Álava. Diputación Foral de Álava. Vitoria-Gasteiz.

LLANOS, A., ARMENDÁRIZ, J., CASTIELLA, A., PEÑALVER, X., SÁENZ DE URTURI, P. y UNZUETA, M.

2009 La Edad del Hierro en el cantábrico oriental y su entorno, en LLANOS ORTIZ DE LANDALUZE, A. Actas Congreso medio siglo de arqueología en el Cantábrico oriental y su entorno. 201-344. Vitoria-Gasteiz.

\section{LÓPEZ DE GUEREÑU GALARRAGA, G.}

1962 Álava, Solar de Arte y de Fe. Caja de Ahorros Municipal de Vitoria. Vitoria.

1989 Toponimia Alavesa seguido de mortuorios o despoblados y pueblos alaveses. Euskaltzaindia. Bilbao.

1998 Voces alavesas. Ayuntamiento de Vitoria-Gasteiz. Euskaltzaindia. Bilbao.

LÓPEZ DE HEREDIA MARTÍNEZ DE SABARTE, J.

2014 La cerámica de la Segunda Edad del Hierro en el País Vasco: estudio tecnológico, funcional y social. Universidad del País Vasco-Euskal Herriko Unibertsitatea.
MADOZ, P.

2000 Diccionario Geográfico-Estadístico-Histórico de España y sus posesiones de Ultramar. Álava. Vitoria-Gasteiz. (Facsímil, 1845-59).

\section{MALUQUER DE MOTES, J.}

1954 El yacimiento hallstático de Cortes de Navarra. Estudio Crítico II. Excavaciones en Navarra VI. Príncipe de Viana. Pamplona.

MANNONI, T. y GIANNICHEDDA, E.

2007 Arqueología. Materias, objetos y producciones. Editorial Ariel. Barcelona.

\section{MARTíNEZ MONTECELO, A. y RODRÍGUEZ FERNÁNDEZ, J.}

2013 Documentación sistemática del arbolado trasmocho: un caso práctico en los Montes Altos de Vitoria, en ARAGÓN RUANO, A., IRIARTE GOÑI, I. y SILVA PANDO, F.J. (eds.). Actas de la IV Reunión de Historia Forestal. Gestión forestal y sostenibilidad: Experiencias históricas. 149-158. Vitoria-Gasteiz, 18-19 octubre 2012. Sociedad Española de Ciencias Forestales.

MARTÍNEZ TORRECILLA, J.M.

2014 Alto de Castejón. Arkeoikuska 2013, 110-112.

MARTÍNEZ TORRECILLA, J.M., SÁNCHEZ ZUFIAURRE, L. y RODRÍGUEZ COSTAS, A.

2012 Alto de Castejón. Arkeoikuska 2011, 115-121.

MENÉNDEZ M., JIMENO A. y FERNÁNDEZ V.M.

2007 Diccionario de Prehistoria. Alianza Editorial. Madrid.

\section{MOHEN, J.P.}

1980 L' Âge du Fer en Aquitaine du VIII au III siècle avant Jesus-Christ. Memoires de la Société Prehistorique Française 14. París.

NÚÑEZ, J., CEPEDA, J.J., ESTEBAN, M., FILLOY, I., GARCÍA, M.L., GIL, E., HERNÁNDEZ, J.A., MARTíNEZ, A., RÉCHIN, F. y RUIZ, A.

2009 La romanización en el cantábrico oriental, en LLANOS ORTIZ DE LANDALUZE, A. Actas Congreso medio siglo de arqueología en el Cantábrico oriental y su entorno. 345-448. Vitoria-Gasteiz

\section{OLAETXEA ELOSEGI, C.}

1991 Prospección arqueológica orientada a la localización de poblados de la Edad del Hierro en Gipuzkoa. Campañas de 1987-88; 1988-89 y 1989-90. Cuadernos de Sección. Prehistoria-Arqueología 4, 197-218.

2000 La tecnología cerámica en la Prehistoria Vasca. Munibe. Suplemento 12. Sociedad de Ciencias Aranzadi. Donostia-San Sebastián

OLAETXEA, C., PEÑALVER, X. y VALDÉS, L.

1990 El Bronce Final y la Edad del Hierro en Gipuzkoa y Bizkaia. Munibe Antropologia-Arkeologia 42, 161-166. 
OREJAS SACO DEL VALLE, A.

1991 Arqueología del paisaje: historia, problemas y perspectivas. AEspA 64, 191-230.

1995 Del "marco geográfico" a la arqueología del paisaje. La aportación de la fotografía aérea. CSIC. Madrid.

2006 Arqueología de los paisajes agrarios e historia rural. Arqueología Espacial 26, 7-19.

OREJAS SACO DEL VALLE, A., RUIZ DEL ÁRBOL MORO, M. y LÓPEZ JIMÉNEZ, O.

2002 Los registros del paisaje en la investigación arqueológica. AEspA 75, 287-311.

PALACIOS MENDOZA, V. y BARRIO LOZA, J.A.

1985 Inventario de arquitectura rural alavesa. II. Rioja alavesa. 2 vols. Diputación Foral de Álava. Vitoria-Gasteiz.

PALACIOS MENDOZA, V. y RODRÍGUEZ FERNÁNDEZ, J.

2004 Patrimonio Arquitectónico de la Cuadrilla de LaguardiaRioja Alavesa. Elementos Menores. Diputación Foral de Álava. Vitoria-Gasteiz.

PALOL, P. de

1974 Álava y la Meseta superior durante el Bronce Final y Primer Hierro. Estudios de Arqueología Alavesa 6, 91-100.

\section{PEÑALVER IRIBARREN, $X$.}

2001 El Bronce Final y la Edad del Hierro en la Euskal Herria atlántica: cromlechs y castros. Complutum 12, 51-71.

2008 La Edad del Hierro. Los vascones y sus vecinos. El último milenio anterior a nuestra Era. Editorial Txertoa. DonostiaSan Sebastián.

\section{QUEROL FERNÁNDEZ, M.A}

2010 Manual de gestión del Patrimonio Cultural. Akal. Madrid.
QUIRÓS CASTILLO, J.A

2003 Prospecciones en la Llanada alavesa. I Campaña. Arkeikuska 2002. 62-68.

QUIRÓS CASTILLO, J.A. y GOBBATO, S.

2004 Prospección y Arqueología de la Arquitectura. Arqueología espacial 24-25, 185-215.

RENFREW, C. y BAHN, P.

2011 Arqueología. Métodos, teorías y práctica. Ed. Akal. Madrid.

RODRÍGUEZ, J., SÁNCHEZ, I. y PALACIOS, V.

2005 Complejo tejero El Enciscal (Lanciego). Arkeikuska 2004, 184-195.

SÁNCHEZ GÓMEZ, F.

1991 El Arma de Artillería en el Reinado de Alfonso XII. Ministerio de Defensa. Madrid.

SESMA, J., LÓPEZ, J.C., MUJIKA, J.A., RODANÉS, J.M. y VEGAS, J.I.

2009 El período calcolítico-Edad del Bronce en el cantábrico oriental y su entorno, en LLANOS ORTIZ DE LANDALUZE, A. Actas Congreso medio siglo de arqueología en el Cantábrico oriental y su entorno. 115-200. Vitoria-Gasteiz.

SOLAUN BUSTINZA, J.L.

2005 La cerámica medieval en el País Vasco (ss. VIII-XIII). Serie EKOB 2. Gobierno Vasco. Vitoria-Gasteiz.

UGARTECHEA, J.M.

1966 Notas sobre el bronce final en el País Vasco. Estudios de Arqueología Alavesa 1, 139-148. 